\title{
Synthesis and use of an asymmetric transfer hydrogenation catalyst based on iron(II) for the synthesis of enantioenriched alcohols and amines
}

\author{
Weiwei Zuo \& Robert H Morris \\ Version Post-print/accepted manuscript \\ Citation Zuo, W., \& Morris, R. H. (2015). Synthesis and use of an asymmetric \\ (published version) transfer hydrogenation catalyst based on iron (II) for the synthesis of \\ enantioenriched alcohols and amines. Nature protocols, 10(2), 241-257.
}

Additional Publisher The final version of this article is available from Nature Publishing

Information Group at http://dx.doi.org/10.1038/nprot.2015.012

How to cite TSpace items

Always cite the published version, so the author(s) will receive recognition through services that track citation counts, e.g. Scopus. If you need to cite the page number of the author manuscript from TSpace because you cannot access the published version, then cite the TSpace version in addition to the published version using the permanent URI (handle) found on the record page.

This article was made openly accessible by $U$ of $T$ Faculty. Please tell us how this access benefits you. Your story matters. 
Synthesis and use of an asymmetric transfer hydrogenation catalyst based on iron(II)

Weiwei Zuo ${ }^{1}$ \& Robert H. Morris ${ }^{1}$

${ }^{1}$ Department of Chemistry, University of Toronto, 80 Saint George St., Toronto, Ont. M5S3H6, Canada

Correspondence to: Robert H. Morris ${ }^{1}$ e-mail: rmorris@ $@$ chem.utoronto.ca

The three part synthesis of trans-\{amine(imine)diphosphine\}chlorocarbonyliron(II) tetrafluoroborate templated by iron salts and starting from commercially available chemicals provides the precatalyst for the efficient asymmetric transfer hydrogenation of ketones and imines. First a dimeric phosphonium salt is prepared as a convenient source of diphenylphosphinoacetaldehyde. Then the enantiopure ligand $(S, S)-\mathrm{PPh}_{2} \mathrm{CH}_{2} \mathrm{CH}_{2} \mathrm{NHCHPhCHPhNH}_{2}$ is made. This ligand is then condensed with diphenylphosphinoacetaldehyde on iron(II), leading to, after treatment with carbon monoxide and sodium chloride, the desired iron catalyst precursor. The $(S, S)$ catalyst is used to reduce prochiral ketones to the $(R)$-alcohol in good to excellent yields and enantioenrichment; certain imines substituted at the nitrogen with the $\mathbf{P}(O) \mathbf{P h}_{2}$ - group are also reduced to the amine in very high yield and enantiopurity. The best ruthenium catalysts provide alcohols in higher ee than this iron complex but at much longer time scales or higher catalyst loadings.

\section{Introduction}

Enantioenriched alcohols and amines are widely used in the pharmaceutical, fragrance, flavoring and fine chemicals industries. ${ }^{1,2}$ One efficient method for their synthesis is the catalytic hydrogenation of prochiral ketones and imines, respectively. ${ }^{3-9}$ The source of the hydrogen for the iron catalyst described here (Figure 1$)^{10}$ is the solvent, isopropanol making this an asymmetric transfer hydrogenation (ATH) catalyst. The ketones and imines are reduced using this iron catalyst at $0.02 \mathrm{~mol} \%$ catalyst loading for ketones and $1 \mathrm{~mol} \%$ loading for imines as summarized in Figure 1. Representative results as are shown in Table 1. The catalyst is activated by 2-8 equivalents of strong base in isopropanol. 
<smiles>[R]C([R])=O</smiles>

$[\mathrm{Fe}]+2-8 \mathrm{KOtBu}$

Ar, isopropanol<smiles>[R][R]([R])([R])O</smiles><smiles>[R]C([R])=N[PH](=O)[PH+]=C(C)C(C)O</smiles>

$[\mathrm{Fe}]+2-8 \mathrm{KOtBu}$

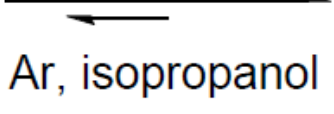<smiles>CC(C)=O</smiles><smiles>[R]C([R7])([18F])N[PH](=O)c1ccccc1</smiles>

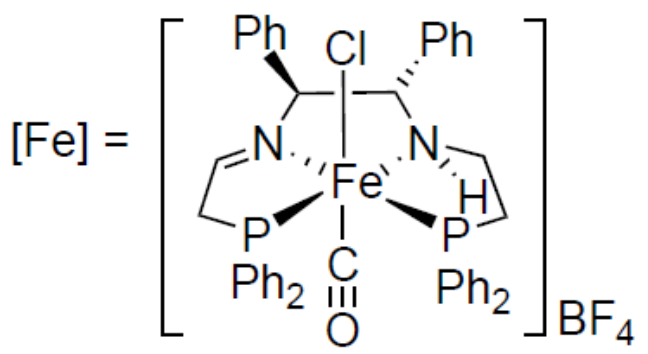

Figure 1 The asymmetric transfer hydrogenation of prochiral ketones and imines by the title iron catalyst system at $0.02 \mathrm{~mol} \%-1 \mathrm{~mol} \%$ catalyst loading. $\mathrm{R}^{1}=\mathrm{Me}, \mathrm{R}^{2}=$ phenyl, 2-naphthyl, 2-pyridyl, 2-furyl, 2-thiopheneyl, isopropyl, 2-styryl. ${ }^{10}$

The remarkable feature of this catalyst is that it surpasses in activity the conventional and advanced ruthenium catalysts used for this process. Since iron is much less harmful and more abundant than ruthenium, this iron complex is a sustainable and green alternative for applications as a catalyst. In addition when this catalyst is eventually made on a large enough scale it will be much less expensive than these ruthenium catalyst systems due to the lower cost of the ligand components. Figure 2 shows the structure of the important ruthenium catalysts while Table 2 provides a comparison of the results with the substrates in Table 1 .

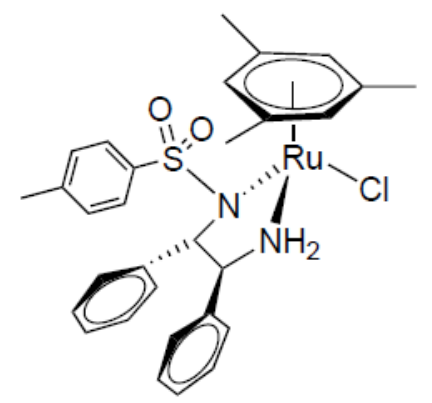

A

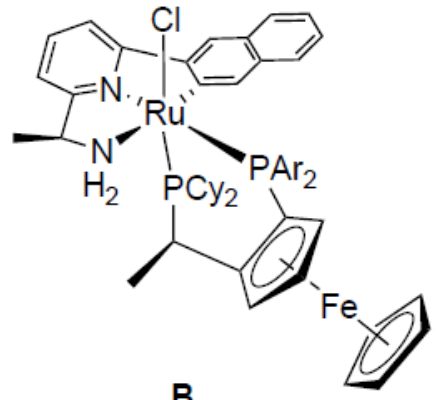

B

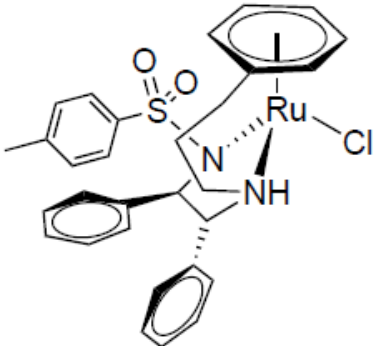

C

Figure 2 The structures of conventional and advanced ruthenium catalysts for ATH.

Complex A was developed by Noyori and coworkers. ${ }^{11,12}$ The complex is available commercially and provides alcohols enriched to high enantiomeric excess. For the substrates acetophenone (entry 1) and 2-acetonaphthone (entry 7) where comparisons are 
available, the iron complex (Fe) provides acceptably high ee on a much shorter time scale with much lower catalyst loadings. Complex A reduces tetralone (entry 10) to the alcohol in much higher ee than the iron complex, but again the rate of reduction using $\mathrm{A}$ is much slower (62 h for $\mathbf{A}$ vs $40 \mathrm{~min}$ for $\mathbf{F e}$ to reach equilibrium). Complex $\mathbf{B}$ developed by Barrata and coworkers $^{13,14}$ does not appear to be available commercially and requires a significant synthetic effort along with the use of an expensive Josiphos ligand. However it can be seen in entries 1, 2, 7 and 11 that it reduces ketones to higher ee and at lower catalyst loadings than Fe. This ruthenium catalyst is still significantly less active, especially considering that the temperature of the reaction is $60^{\circ} \mathrm{C}$ for $\mathbf{B}$ vs $28^{\circ} \mathrm{C}$ for $\mathbf{F e}$ and yet the times to equilibrium are still much longer for $\mathbf{B}$. Finally tethered Noyori-type catalysts like $\mathbf{C}$ have been developed by Wills and coworkers. ${ }^{15-17}$ They are best used with triethylamine/formic acid mixture as solvent to drive the reductions to completion, making product separation more challenging than from the isopropanol solutions used in the iron catalysis. Again the enantioselectivity of ketone reduction, where comparisons are available (entries 1,11-13), are higher for the ruthenium catalyst but the activity is much lower, reductions taking many hours compared to minutes for Fe. All of these catalytic systems, once activated, must be protected from oxygen in the air. The presence of water is not a problem, at least for the iron catalyst.

This protocol describes (i) the synthesis of a phosphonium dimer by deprotection of the protected phosphine-aldehydes in acidic solution; (ii) the synthesis of an enantiopure tridentate ligand $(S, S)-\mathrm{PPh}_{2} \mathrm{CH}_{2} \mathrm{CH}_{2} \mathrm{NHCHPhCHPhNH}_{2}$ by reduction and hydrolysis of the imine linkages in a bis-tridentate iron complex and (iii) the synthesis of the trans-\{amine(imine)diphosphine\}chlorocarbonyliron(II) tetrafluoroborate complex by a multicomponent template synthesis and metal complex ligand exchange reactions. Each synthesis proceeds cleanly with high selectivity and high yield. The scale of the whole synthesis is limited by that of the tridentate ligand, due to (i) the potential side reactions in making the bis-tridentate iron (II) complex and (ii) the accompanying problems with using larger quantity of lithium aluminum hydride. The analytically pure trans-\{amine(imine)diphosphine $\}$ chlorocarbonyliron(II) tetrafluoroborate is easily isolated in a good yield by recrystallizing the crude product in hot methanol. The syntheses of the phosphonium dimer and the tridentate ligand $(S, S)-\mathrm{PPh}_{2} \mathrm{CH}_{2} \mathrm{CH}_{2} \mathrm{NHCHPhCHPhNH}_{2}$ take $20 \mathrm{~h}$ and $8 \mathrm{~h}$ respectively, while the synthesis of the finally iron complex takes $56 \mathrm{~h}$ due to the relative long periods of the ligand exchange reactions and the recrystallization process.

A general procedure is provided for the catalytic asymmetric transfer hydrogenation (ATH) of a ketone, acetophenone, to afford the enantioenriched product, $(R)$-1-phenylethanol using the $(S, S)$ form of the catalyst, as well for the ATH of other ketone and imine substrates and the achiral reduction of two aldehydes (Table 1).

\section{Experimental design}

The protocol includes the syntheses of the phosphonium dimer, the enantiopure tridentate ligand $(S, S)-\mathrm{PPh}_{2} \mathrm{CH}_{2} \mathrm{CH}_{2} \mathrm{NHCHPhCHPhNH}_{2}$ and finally the trans-\{amine(imine)diphosphine $\}$ chlorocarbonyliron(II) tetrafluoroborate catalyst precursor. The syntheses of (S,S)- $\mathrm{PPh}_{2} \mathrm{CH}_{2} \mathrm{CH}_{2} \mathrm{NHCHPhCHPhNH}{ }_{2}$ and the iron (II) complex are scaled up by a factor of ten compared to our original publication. ${ }^{10}$ Further purification of the iron 
complex by first washing the crude product with water in dichloromethane (DCM) solution and the following recrystallization in hot methanol are straightforward and produce the iron complex in high yield and purity. The use of the catalyst in the ATH of ketones and imines (Figure 1) is also described.

\section{Synthesis of the phosphonium dimer}

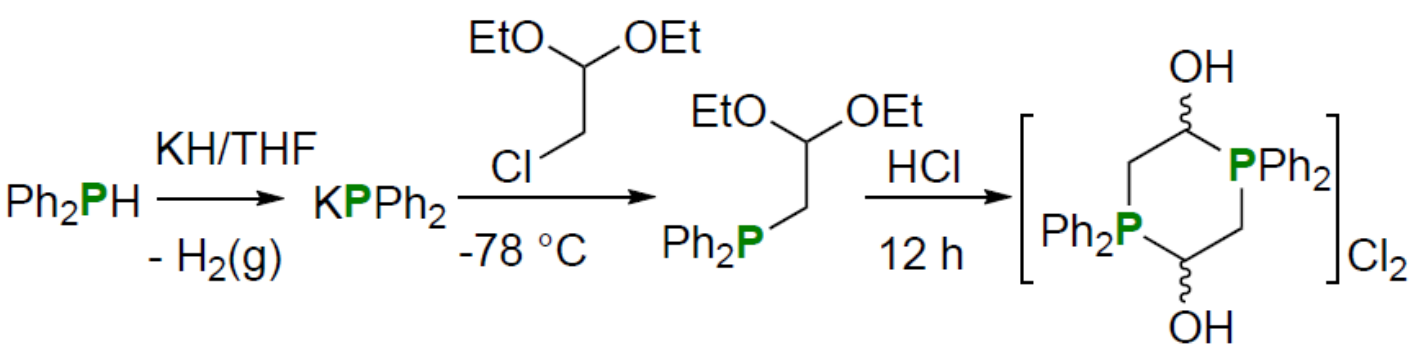

Figure 3 Synthesis of the phenyl-substituted phosphonium dimer

The phosphonium dimer was synthesized by deprotection of diphenylphosphinoacetaldehyde diacetal, in acidic solution. ${ }^{18}$ Reaction of the commercially available diphenylphosphine $\left(\mathrm{HPPh}_{2}\right)$ with potassium hydride $(\mathrm{KH})$ generates the phosphide $\left(\mathrm{KPPh}_{2}\right)$, which can undergo nucleophilic attack on the protected aldehyde (chloroacetoaldehyde diethyl acetal, $\left.\mathrm{ClCH}_{2} \mathrm{CH}(\mathrm{OEt})_{2}\right)$ to give a protected phosphine-aldehyde intermediate. Deprotection of the phosphine-aldehyde diethyl acetals in acidic media gives the desired dimer as a white, air-stable solid in $82 \%$ yield. This led our group to discover a simple method of producing such phosphonium compounds when the phosphorus atoms bear electron-donating substituents and a high yielding method for the selective formation of a tetrameric macrocycle. ${ }^{18}$ Cyclic phosphonium dimers with similar structure but having isopropyl, ethyl or cyclohexyl substituents at the phosphorus atoms are prepared in a simpler fashion by directly reacting the corresponding secondary phosphine with the bromoacetoaldehyde diethyl acetal $\left(\mathrm{BrCH}_{2} \mathrm{CH}(\mathrm{OEt})_{2}\right)$ to produce phosphonium salts that were then hydrolyzed. ${ }^{18,19}$ This method works because of the greater nucleophilicity of the dialkylphosphines. It can be expanded to other protected phosphine-aldehydes with different linkers between the phosphine and formyl groups to prepare phosphonium salts with different ring sizes. ${ }^{18}$ In the case of trifluoromethylaryl substituents, the phosphine aldehydes do not react to form phosphonium dimers. ${ }^{20}$

For the deprotection of the diphenylphosphinoacetaldehyde diethylacetal, the reaction mixture is usually permitted to stir overnight to ensure that the reaction goes to completion. Fortunately, it was found that the phosphonium product precipitated from the reaction mixture so that very pure product can be obtained in high yield by simple vacuum filtration. In addition, this compound is not soluble in water and therefore can be washed to completely remove the inorganic salts $(\mathrm{KCl}$ or $\mathrm{KBr})$ by stirring with water at room temperature for more than $2 \mathrm{~h}$ followed by filtration though a filter paper.

An alternative method to make the nucleophilic phosphide required in the reaction involves 
the reaction of chlorodiphenylphosphine with an excess (5 eq.) of finely divided lithium in THF at room temperature for 30 min under an inert atmosphere. ${ }^{21}$ The advantage of using this procedure is that the chlorodiphenylphosphine is cheaper than diphenylphosphine. However the removal of the unreacted lithium and the product lithium chloride by filtration prior to the addition of chloroacetoaldehyde diethyl acetal is time-consuming and difficult, as the inorganic particles are very fine and can easily block the filter.

\section{Synthesis of the tridentate ligand $(S, S)-\mathrm{PPh}_{2} \mathrm{CH}_{2} \mathrm{CH}_{2} \mathrm{NHCHPhCHPhNH}_{2}$}

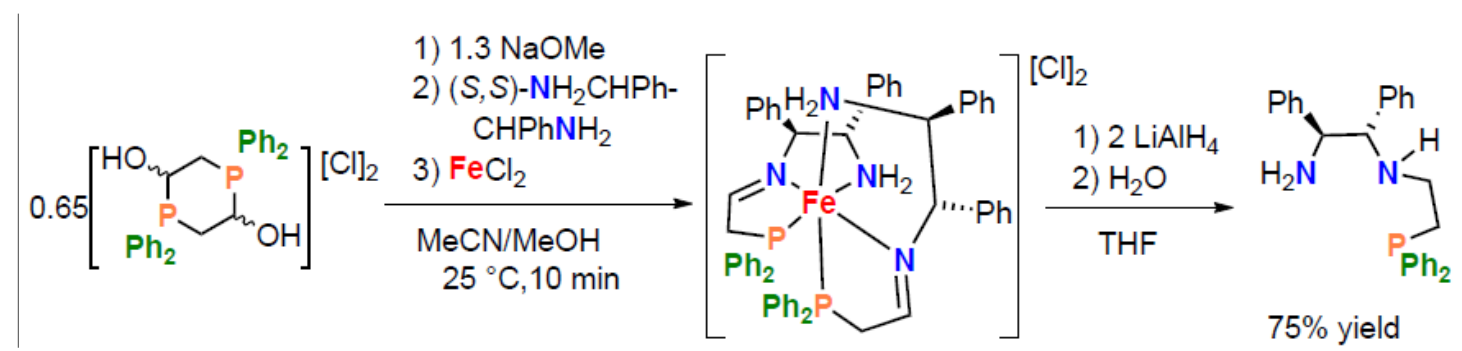

Figure 4 Synthesis of the tridentate ligand $(S, S)-\mathrm{PPh}_{2} \mathrm{CH}_{2} \mathrm{CH}_{2} \mathrm{NHCHPhCHPhNH}_{2}$. Adapted from reference ${ }^{10}$.

The enantiopure tridentate ligand (S,S)- $\mathrm{PPh}_{2} \mathrm{CH}_{2} \mathrm{CH}_{2} \mathrm{NHCHPhCHPhNH} \mathrm{NH}_{2}$ is selectively synthesized via a multicomponent reaction templated by iron(II) utilizing an air-stable phosphonium precursor, base, $(S, S)$-1,2-diphenyl-1,2-diaminoethane (S,S-dpen) and $\mathrm{FeCl}_{2} \cdot{ }^{10}$ This phosphonium dimer releases reactive $\alpha$-phosphinoacetaldehyde when it is treated with base (NaOMe). The aldehyde then undergoes Schiff-base condensation with the enantiopure diamine at iron(II) to form an iron complex as one diastereomer with two tridentate P-N-N ligands incorporating phosphine, imine, and amine donors. ${ }^{19,22}$ This iron complex is treated with lithium aluminum hydride to reduce the imine linkages and the resulting mixture is then hydrolyzed to release the enantiopure compound $(S, S)-\mathrm{PPh}_{2} \mathrm{CH}_{2} \mathrm{CH}_{2} \mathrm{NHCHPhCHPhNH}_{2}$ in high yield and approx. $90 \%$ purity. This is pure enough to be used directly in the next step.

This method of preparation provides enantiopure compounds that were hitherto unobtainable possibly due to their sensitivity to both acid and base. Related compounds with ethyl, tolyl and xylyl substituents at the phosphine atoms can also be made with this method with high yield. ${ }^{10}$ However, it does not work for the cyclohexyl analogue.

This synthesis is optimized on a $4.7 \mathrm{mmol}$ scale of the $S, S$-dpen starting material. Scaling down the amounts is usually possible, but scaling up at the present may lead to some problems as we will discuss later.

The timing of the template reaction is crucial, as extended reaction time results in the formation of a side product which is probably the P-N-N-P tetradentate bis(imine) iron(II) complex based on previous observations. ${ }^{10,22}$ The progress of this reaction can be monitored by ${ }^{31} \mathrm{P}$ NMR using a $\mathrm{D}_{2} \mathrm{O}$ or benzene- $\mathrm{d}_{6}$ insert (see the Supplementary Information). The desired bis-tridentate complex resonates at $\delta 58.5 \mathrm{ppm}$. Once another signal at $\delta 73.2 \mathrm{ppm}$ emerges, the solvent should be removed as soon as possible. The concentrations of the reactants of this reaction are also very crucial. Higher concentration easily leads to the 
formation of a side product resonating at $\delta 73.2 \mathrm{ppm}$. To get a complete conversion of $S, S$-dpen, a slight excess of the phosphonium dimer ( 0.65 equiv.) is used.

A limitation on the scale of the synthesis of this $(S, S)-\mathrm{PPh}_{2} \mathrm{CH}_{2} \mathrm{CH}_{2} \mathrm{NHCHPhCHPhNH}_{2}$ ligand is caused by the time to evaporate the methanol, as larger scales require more solvent and longer evaporation times, during which the side reaction to form the bis(imine) P-N-N-P iron (II) complex can occur. ${ }^{10,22}$ Such a bis(imine) P-N-N-P iron complex will give impurities in the final product after the reduction and the hydrolysis workups. The solvent methanol was removed in the air using a rotary evaporator as quickly as possible. We normally use two rotary evaporators in parallel in order to minimize the evaporating time. In addition, the temperature of the water bath of the rotary evaporator should not exceed $30{ }^{\circ} \mathrm{C}$. This takes around $20 \mathrm{~min}$ to completely remove the solvent under our conditions; NMR analysis of the final product indicates that under such conditions, the side reaction can be avoided.

In terms of other iron precursors, $\mathrm{FeBr}_{2}$ also works but the rate is much faster, leading more easily to side reactions, while the use of $\left[\mathrm{Fe}\left(\mathrm{H}_{2} \mathrm{O}\right)_{6}\right]\left[\left(\mathrm{BF}_{4}\right)_{2}\right]$ usually leads to a mixture of several unknown products.

For the reduction reaction, various hydride reductants including $\mathrm{LiAlH}_{4}, \mathrm{NaBH}_{4}$ and superhydride have been used, but only $\mathrm{LiAlH}_{4}$ gives the pure and clean product. Many side products are obtained when using the other reductants. In addition, at least 2 equivalents of $\mathrm{LiAlH}_{4}$ relative to that of $S, S$-dpen are required to make sure no other side products being formed. The optimum quantity of the required $\mathrm{LiAlH}_{4}$ is 3 to 4 equivalents.

Problems related to the use of $\mathrm{LiAlH}_{4}$ also limit the scale of the whole synthesis of the iron catalyst precursor. Each time only $1.5 \mathrm{~g}$ at most of $S, S$-dpen can be used as the starting material.

Water, methanol and ethanol have been used as a proton source to neutralize aluminum hydrides at the end of the reaction. Only the use of water gave the expected product. $\mathrm{LiAlH}_{4}$ is a reactive compound that readily catches fire when exposed to air and therefore must be handled with care using inert atmosphere techniques as is described in this procedure. The reaction mixture in THF was first cooled to approx. $-50{ }^{\circ} \mathrm{C}$ with liquid nitrogen prior to the addition of water, and this addition should be done drop-wise in the beginning, waiting after each drop until the bubbling caused by the previous drop has ceased.

The $(S, S)-\mathrm{PPh}_{2} \mathrm{CH}_{2} \mathrm{CH}_{2} \mathrm{NHCHPhCHPhNH}_{2}$ ligand is finally extracted from the crude product mixture by use of dichloromethane (DCM). Workup in the air is necessary, presumably due to the oxidation of the low-valent iron species produced in the previous step to iron oxides, which can be easily removed by filtration through a pad of Celite. This produces essentially pure material in good yield via subsequent drying of DCM under reduced pressure; further purification is not required.

\section{Synthesis of the trans-\{amine(imine)diphosphine\}chlorocarbonyliron(II) tetrafluoroborate precatalyst.}




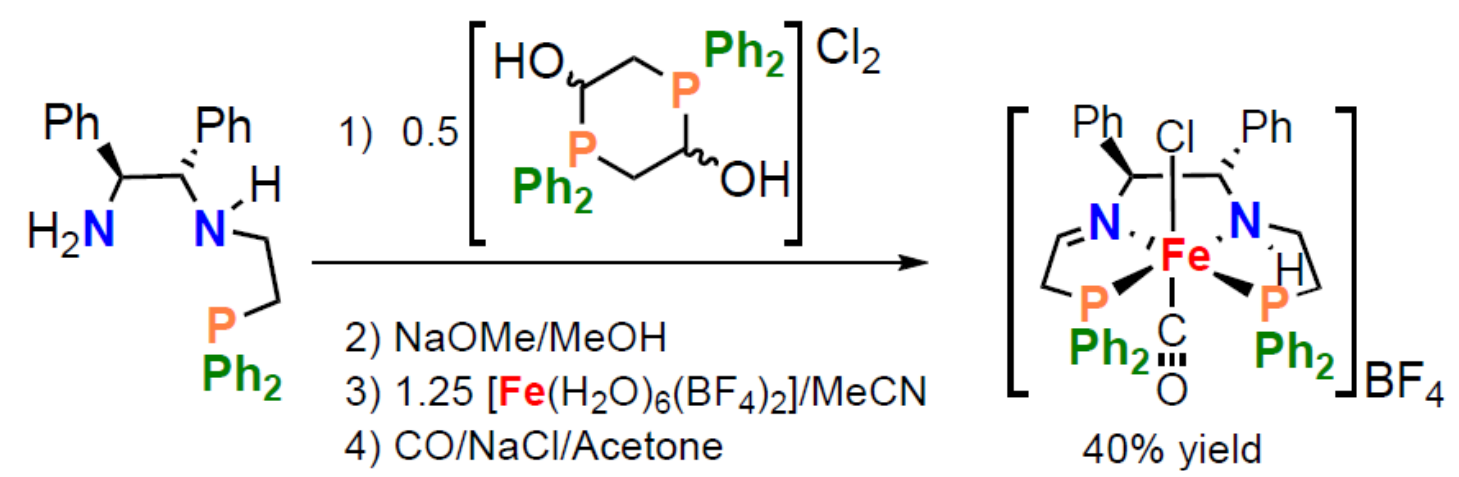

Figure 5 Synthesis of the trans-\{amine(imine)diphosphine $\}$ chlorocarbonyliron(II) tetrafluoroborate precatalyst.

The precatalyst trans-[ $\left.\mathrm{Fe}(\mathrm{CO})(\mathrm{Cl})\left(\mathrm{PPh}_{2} \mathrm{CH}_{2} \mathrm{CH}=\mathrm{NCHPhCHPhNHCH} \mathrm{CH}_{2} \mathrm{PPh}_{2}\right)\right] \mathrm{BF}_{4}$ shown in Figure 1 is prepared in a facile and economical two-step synthesis. The first step utilizes a direct template synthesis method similar to that which we used to prepare other tridentate ligands and related P-N-N-P bis(imine) iron complexes. ${ }^{10,22,23}$ The phosphonium salt is reacted with base to release the $\alpha$-phosphinoacetaldehyde, which condenses with the $(S, S)-\mathrm{PPh}_{2} \mathrm{CH}_{2} \mathrm{CH}_{2} \mathrm{NHCHPhCHPhNH}_{2}$ ligand on the iron cation template to form an amine(imine)diphosphine P-N-NH-P bis(acetonitrile) iron(II) complex trans-[Fe $\left.(\mathrm{MeCN})_{2}\left(\mathrm{PPh}_{2} \mathrm{CH}_{2} \mathrm{CH}=\mathrm{NCHPhCHPhNHCH} \mathrm{CH}_{2} \mathrm{PPh}_{2}\right)\right]\left[\mathrm{BF}_{4}\right]_{2}$. A ligand exchange reaction with $1 \mathrm{~atm}$ of carbon monoxide and sodium chloride in acetone leads to the iron complex with the desired partially saturated P-NH-N-P framework in an acceptable overall yield. The crystalline and analytically pure product is easily isolated in good yield by recrystallization from hot methanol.

Other related iron complexes with either identical or different substituents on the two P atoms can also be made with similar procedure. These substituents include isopropyl, cyclohexyl, phenyl, tolyl, and xylyl etc. ${ }^{10}$

For the reaction with carbon monoxide in the presence of $\mathrm{NaCl}$ in acetone, the reaction is allowed to stir at a flow of 1 atm $\mathrm{CO}$ gas at room temperature for $3 \mathrm{~h}$. This reaction is repeated once in acetone by removing the solvent after the first $3 \mathrm{~h}$ of reaction, followed by adding a new portion of acetone to the resulting yellow solid and then stirring the reaction for an additional $3 \mathrm{~h}$. Longer reaction time may be necessary for larger reaction scales, and in such cases the use of overnight stirring is usually required.

For the final workup, in the original publication the inorganic salts were removed by filtration of the DCM solution through a pad of Celite. ${ }^{10}$ For the current larger scale case, to make sure these salts are completely removed, we wash the DCM solution of the crude product with water in the air by using a separatory funnel. NMR analysis indicates that if this manipulation together with the following DCM evaporation is finished within $1 \mathrm{~h}$, no decomposition of the iron complex is detected. The extremely pure and crystalline product can be produced via recrystallization in hot methanol at $95{ }^{\circ} \mathrm{C}$ in a sealed bomb (Figure 6, see Figure S12 for larger size of the bomb). The weight ratio between the crude product to the solvent is 1:10.5. 


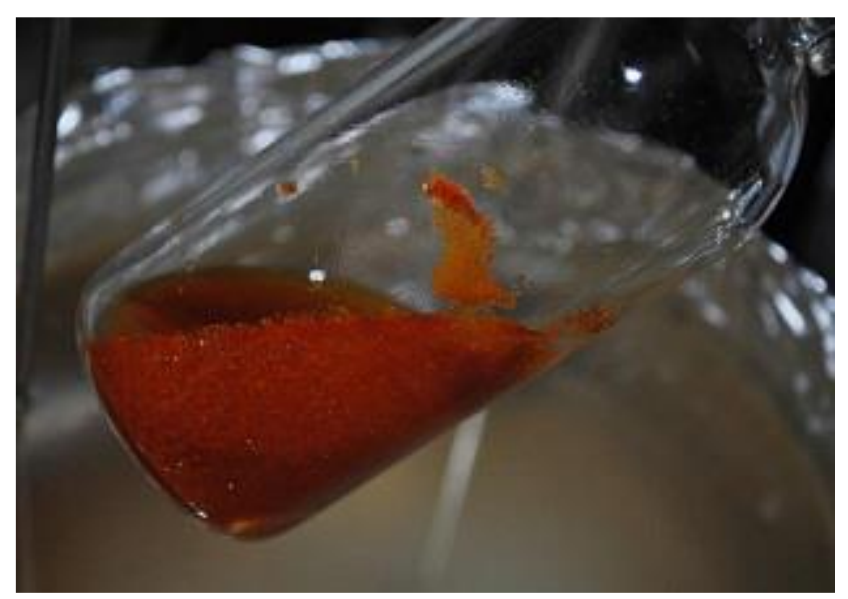

Figure 6 Crystals oftrans- $\left[\mathrm{Fe}(\mathrm{CO})(\mathrm{Cl})\left(\mathrm{PPh}_{2} \mathrm{CH}_{2} \mathrm{CH}=\mathrm{NCHPhCHPhNHCH}{ }_{2} \mathrm{CH}_{2} \mathrm{PPh}_{2}\right)\right] \mathrm{BF}_{4}$

\section{Catalytic asymmetric transfer hydrogenation of ketones and imines}

In our original publication, ${ }^{10}$ we reported the fast asymmetric reduction of a series of ketone and imine substrates by using the P-N-NH-P iron precatalysts activated by 8 eq. of base in isopropanol. Although the catalytic activity is very high, there are two problems with this procedure before it is practically applicable in the synthesis of chiral alcohols. First, due to the thermodynamic character of the transfer hydrogenation reactions for most ketones, there is an equilibrium between ketone, isopropanol and chiral alcohol, acetone, and as a result the substrate cannot be completely converted. Second, to achieve the highest conversion of the substrate, it normally takes some time ( $3 \mathrm{~min}$ to $1 \mathrm{~h}$ ), during which the erosion of the enantiomeric excess of the initially formed chiral alcohols occurs and as a result the final products obtained usually have reduced enantiopurities. In order to synthesize chiral alcohols with the highest enantiopurities and highest yields, we modified our previous procedure for the asymmetric transfer hydrogenation reactions. For acetophenone, under the same conditions as before the catalytic reaction is let to run for $30 \mathrm{sec}$ during which time around $60 \%$ of the substrate has been converted while within such a short period of time the erosion of the enantiomeric excess is not significant (around 90\% ee obtained after $30 \mathrm{sec}$ of reaction time). The catalytic reaction is then quenched immediately with oxygen by bringing the reaction vial out of the glovebox and exposing the solution to air. The solvent isopropanol and the generated acetone are removed under reduced vacuum and the obtained mixture is then subjected to reduction again for an additional $30 \mathrm{sec}$ with the same conditions. Similar to our previous observations in the direct hydrogenation of acetophenone using the same precatalyst ${ }^{21}$ it is found that the catalytic activity is not dependent on the concentration of acetophenone. Therefore, $30 \mathrm{~s}$ of the second step is long enough for the complete conversion of the residual substrate. By this 2-step method, $R$-1-phenylethanol is obtained in $90 \%$ ee with $>99 \%$ yield (Table 1, entry 1 and Figure S19). The only disadvantage of this procedure is that the turnover number (TON, 3060) of the acetophenone is half of that of the previous procedure.

This procedure is believed to work for other substrates on the basis of the reaction kinetics of these substrates in our previously standard procedure where these substrates are reduced in only one step (Table 1, entries 8-14). ${ }^{21}$ However, for the activated imine substrates, benzaldehyde and $\alpha, \beta$-unsaturated aldehyde our previous procedure has already been able to 
fully convert them (entries 3-6). This method also works for the more enantioselective precatalyst possessing xylyl substituents at both phosphine atoms, and thus is able to produce more enantiopure products while still with very high yields (>99\%). In addition, in unpublished research, we have found that by varying the structure of the catalyst precursor, via changing the substituents at the phosphine atoms, enantiomeric excess of greater than 99\% of $R$-1-phenylethanol can be obtained. With this catalyst precursor and the current modified procedure, chiral alcohols of higher enantiopurities and high yields can be expected to be prepared easily.

In general, our protocol is practically applicable for the reduction of four categories of substrates in the synthesis of corresponding products (Table 1, entries 1-8) on a small scale. (1) Aryl-alkyl (and substituted aryl-alkyl), 2-naphthyl-alkyl and diaryl ketones. For these substrates, the current modified procedure normally features high ee (>90\%) and high conversions (>99\%). (2) 3,5-bistrifluoromethylacetophenone (entry 2). The current catalyst produces the alcohol in $91 \%$ ee at full conversion but using the more enantioselective precatalyst having the xylyl substituents at both phosphine atoms ${ }^{10}$ leads to the production of $(R)$ alcohol with $98 \%$ ee and full conversion. (3) $\alpha, \beta$-unsaturated and aryl aldehydes (entry 3 , $4)$. Our iron catalyst is very efficient in the reduction of either aryl or $\alpha, \beta$-unsaturated aldehydes and only one-step catalysis is required. Usually the catalytic activity is very high and the reduction of $\alpha, \beta$-unsaturated aldehyde is chemoselective, only furnishing unsaturated alcohols as the product with high yield (>99\%). (4) $\mathrm{N}$-(diphenylphosphinoyl) group (-P(O) $\left.\mathrm{Ph}_{2}\right)$ protected imines (entry 5,6 ). Only one-step catalysis is required and both the yield and the enantioselectivity are very high. Besides these substrates, the current protocol also works well for other ketone substrates such as alkyl ketones, heteroaryl ketones, with very high yields although in some cases the enantiomeric excesses of the product alcohols are low (entries 9-13).

The current procedure is very fast and convenient to make chiral alcohols and protected amines and it is practically applicable for small-scale synthesis of these alcohol and amines. The production of the alcohol product in approx. $1 \mathrm{~g}$ scale has been demonstrated to be feasible by simply increasing the scale of the catalytic reaction under the same conditions. The yield can be very high in each substrate case if the 2-step or even 3-step catalysis is employed. The relatively pure crude product mixture can be obtained by simply evaporating the solvent isopropanol under vacuum. The current procedure only needs 6 vials, several stirring bars and some Pasteur pipettes. Only isopropanol is needed as it acts as both the reductant and solvent. Only trace of potassium tert-butoxide is required to activate the precatalyst. No heating and no high pressure resistant reactor are required. However, as the catalyst is sensitive to oxygen, an oxygen-free glovebox is required and the isopropanol should be rigorously oxygen-free. The catalytic reaction is not water-sensitive. Another main disadvantage of our current protocol is the inherently low enantioselectivities for some substrates especially for those with less substituent bulk on the acyl group. In addition, the iron catalytic system is not able to reduce non-protected imine substrates as the initially formed amine products can easily deactivate the catalyst. Since the synthesis of the iron catalyst is very modular this problem may be overcome in the future by changing substituents on the phosphorus or the backbone of the ligand. 


\section{PROCEDURE}

\section{Synthesis of the phosphonium dimer $\left(\mathrm{PPh}_{2} \mathrm{CH}_{2} \mathrm{CHOH}-\right)_{2} \mathrm{Cl}_{2}$ TIMING $20 \mathrm{~h}$}

1. In the glovebox (argon or nitrogen filled), weigh potassium hydride (KH, $0.86 \mathrm{~g}, 21.5$ mmol, by washing $\mathrm{KH}$ in oil with hexanes) into a Schlenk flask $(250 \mathrm{~mL})$ that is charged with a Teflon-coated stirring bar. In a separate vial (volume $20 \mathrm{~mL}$ ), dissolve diphenylphosphine ( $3.20 \mathrm{~g}, 17.2 \mathrm{mmol})$ in THF $(20 \mathrm{~mL})$ by stirring with a Teflon-coated stirring bar.

CAUTION KH reacts violently with acids and ignites upon contact with oxidants, including oxygen. $\mathrm{KH}$ causes severe burns if it is brought into contact with the skin, and, in the dry state, it is pyrophoric.

CRITICAL STEP The solvent THF should be dry and degassed. Diphenylphosphine can be oxidized by the oxygen in the air, and as a result, care must be taken in its handling to avoid its oxidation.

2. Pour the THF solution of diphenylphosphine into the Schlenk flask $(250 \mathrm{~mL})$ that contains $\mathrm{KH}$ with vigorous stirring.

3. Add more dry and degassed THF to make the total volume of the solution around $120 \mathrm{~mL}$. A red solution should be observed together with the bubbling of dihydrogen gas (Figure S1).

\section{TROUBLESHOOTING}

CAUTION For a larger scale reaction, releasing of $\mathrm{H}_{2}$ gas in the glovebox is not good for the atmosphere of the glovebox, and the reaction can be done in the vacuum line by releasing the $\mathrm{H}_{2}$ gas to a mercury bubbler in a well-vented fume hood.

4. Let the reaction stir at room temperature for $1 \mathrm{~h}$.

5. Seal the Schlenk flask with a rubber septum, turn off the valve of the Schlenk flask and then bring it out of the glovebox. Cool the reaction mixture to $-78{ }^{\circ} \mathrm{C}$ by using a dry ice/acetone cooling bath in a hemispherical Dewar flask.

6. In the glovebox, place chloroacetaldehyde diethyl acetal $(3.93 \mathrm{~g}, 25.8 \mathrm{mmol})$ into a disposable syringe $(5 \mathrm{~mL})$ equipped with a stainless needle $(0.8 \mathrm{~mm} \times 40 \mathrm{~mm})$ and then stopper the needle by sticking it into rubber (e.g. a rubber septum). Bring the syringe out of the glovebox and then inject the chloroacetaldehyde diethyl acetal into the THF solution of the previous step dropwise over the period of 1 min with vigorous stirring.

CRITICAL STEP The chloroacetaldehyde diethyl acetal should be degassed using the freeze-pump-thaw degassing method and dried with $4 \AA$ molecular sieves and stored in the glovebox prior to use.

7. Remove the cooling bath and let the temperature of the reaction mixture slowly rise to room temperature while the solution is being stirred. In total, the solution is stirred for $1 \mathrm{~h}$ starting from the removal of the cooling bath. The color of the solution changes slowly from red to slightly yellow. 
8. Add the diluted hydrochloric acid solution ( $3 \mathrm{~mL}$ of $36.5 \mathrm{wt} \%$ hydrochloric acid diluted by $10 \mathrm{~mL} \mathrm{H}_{2} \mathrm{O}$ ) to the above reaction mixture and let the reaction mixture stir at room temperature overnight to produce a white precipitate (Figure S2).

CAUTION $\mathrm{HCl}(\mathrm{aq})$ is highly corrosive, and its vapors irritate the eyes and throat. Carry out this step in a well-vented fume hood.

9. Isolate the product by vacuum filtration using a Büchner funnel and a filter paper in the air. (Figure S3). Keep the white solid and discard the filtrate.

10. Put the obtained white solid and the stirring bar back into the Schlenk flask and add 10 $\mathrm{mL}$ of $\mathrm{H}_{2} \mathrm{O}$. Let the resulting white suspension stir at room temperature for $2 \mathrm{~h}$.

CRITICAL STEP It is essential to remove all the inorganic salts from the product; otherwise the quantity of the phosphonium dimer used in the next step is not accurate. Washing the product with $\mathrm{H}_{2} \mathrm{O}$ twice is advised.

11. Isolate the product by vacuum filtration using a Büchner funnel and a filter paper in the air as Step 9. Keep the white solid and discard the filtrate.

12. Wash the product with THF $(10 \mathrm{~mL})$ by adding THF into the product pad inside the Büchner funnel while the vacuum is on. Keep the vacuum for 10 min until the product is almost dry. Dry the product under high vacuum $\left(1 \times 10^{-1} \mathrm{mbar}\right)$ for more than $3 \mathrm{~h}$; we put the product inside the antichamber of the glovebox under vacuum overnight.

PAUSE POINT This compound is usually obtained in $82 \%$ yield, and it can be stored in the air for several months without noticeable loss of purity. 


\section{Synthesis of the tridentate ligand $(S, S)-\mathrm{PPh}_{2} \mathrm{CH}_{2} \mathrm{CH}_{2} \mathrm{NHCHPhCHPhNH}_{2}$. TIMING $8 \mathrm{~h}$}

13. In the glovebox, dissolve $\mathrm{FeCl}_{2}(0.6 \mathrm{~g}, 4.7 \mathrm{mmol})$ in methanol $(20 \mathrm{~mL})$ in a vial (volume $20 \mathrm{~mL}$ ) with stirring. In a separate vial (volume $20 \mathrm{~mL}$ ), dissolve $(S, S)$-1,2-diphenyl-1,2-diaminoethane $(S, S$-dpen $)(1 \mathrm{~g}, 4.7 \mathrm{mmol})$ in methanol $(20 \mathrm{~mL})$ with stirring. Weigh sodium methoxide $(0.33 \mathrm{~g}, 6.1 \mathrm{mmol})$ and the phosphonium dimer $(1.60 \mathrm{~g}, 3.0$ mmol) into a flask $(500 \mathrm{~mL})$ that is charged with a Teflon-coated stirring bar.

CRITICAL STEP The solvent methanol should be dry and degassed. The amount of the phosphonium dimer is important for the full conversion of $S, S$-dpen. A smaller quantity of phosphonium dimer will lead to incomplete conversion of $S, S$-dpen, which will be left in the final product, while too much phosphonium dimer will cause side reactions forming impurities which will also be left in the final product. For the same reason, excess $\mathrm{FeCl}_{2}(1$ equiv. instead of the required 0.5 equiv.) is used.

14. Add dry and degassed methanol $(200 \mathrm{~mL})$ into the flask and let the resulting colorless solution stir at room temperate for $2 \mathrm{~min}$.

CRITICAL STEP The concentration of this reaction is critical; a higher concentration easily leads to side reactions while a lower concentration will result in incomplete reaction.

15. Add the $S, S$-dpen and $\mathrm{FeCl}_{2}$ solutions in sequence into the above colorless solution. The color of the solution instantaneously becomes red. Seal the flask and let the red solution stir at room temperature for $15 \mathrm{~min}$ inside the glovebox (Figure S4).

CRITICAL STEP Reaction time longer than $10 \mathrm{~min}$ is required for the full conversion of $S, S$-dpen. However, reaction time longer than $30 \mathrm{~min}$ is likely to cause side reactions. The reaction can be monitored by ${ }^{31} \mathrm{P}\left\{{ }^{1} \mathrm{H}\right\}$ NMR using a $\mathrm{D}_{2} \mathrm{O}$ insert (Figure S5) to make sure the side product resonating at $\delta 73.2 \mathrm{ppm}$ does not appear.

CAUTION The methanol is volatile and the flask should be sealed as the methanol gas is harmful to the catalyst bed of the glovebox.

16. Bring the flask out of the glovebox and then separate the solution into two portions with approximately equal volumes in two one-neck round-bottom flasks. Remove the solvents of the two portions in parallel using two rotary evaporators (Figure S6).

CRITICAL STEP The temperature of the water bath should not exceed $30{ }^{\circ} \mathrm{C}$; otherwise side reactions will occur. It takes about 20 min for complete removal of the solvent. It is essential to remove all of the methanol from the reaction mixture as it can react with lithium aluminum hydride $\left(\mathrm{LiAlH}_{4}\right)$ in the next step. Prolonged (longer than $30 \mathrm{~min}$ ) drying under high vacuum is advised. Alternatively, traces of methanol can be removed azeotropically by adding THF ( $10 \mathrm{ml})$ to the solid followed by evaporation with a rotary evaporator.

17. Remove the water on the outer wall of the flasks completely and bring the two flasks inside the glovebox. For one flask, use a spatula to scratch down the red solid from the wall of the flask and then combine the red solid with that in the other flask.

CRITICAL STEP The water on the outer wall of the flask comes from the water bath of the rotary evaporator. It must be removed completely. 
18. In the same glovebox, weigh lithium aluminum hydride $(0.71 \mathrm{~g}, 18.8 \mathrm{mmol}, 4$ eq. $)$ into a vial $(4 \mathrm{~mL})$. Add this lithium aluminum hydride portion-wise to THF $(100 \mathrm{~mL})$ in a separate round-bottom flask $(250 \mathrm{~mL})$ with vigorous stirring. Let the solution stir for 30 seconds.

CRITICAL STEP The quantity of $\mathrm{LiAlH}_{4}$ should be greater than 2 equivalents relative to that of $S, S$-dpen to ensure a complete reaction. The optimized quantity is 4 equivalents relative to that of the $S, S$-dpen. More $\mathrm{LiAlH}_{4}$ will cause serious handing problems when quenching in the subsequent hydride quenching reaction.

CAUTION $\mathrm{LiAlH}_{4}$ reacts vigorously with water, acids and alcohols and can easily catch fire. The $\mathrm{LiAlH}_{4}$ should be handled and stored under an inert atmosphere. Addition of $\mathrm{LiAlH}_{4}$ to THF can be surprisingly exothermic. Small quantities of $\mathrm{LiAlH}_{4}$ should be destroyed by quenching with cold isopropanol. The solvent THF should be dry and degassed.

19. Pour the $\mathrm{LiAlH}_{4}$ solution in THF into one of the flask that contains residual red product on the flask wall in Step $\mathbf{1 7}$ to rinse the residue product. Add the resulting brown solution to the other flask that contains the majority of red solid with vigorous stirring. Let the brown solution stir for $5 \mathrm{~min}$ at room temperature to afford a black brown solution (Figure S7).

20. Seal the flask and then bring it out of the glovebox. Add more THF $(50 \mathrm{~mL})$ to the flask. Cool the solution for $1 \mathrm{~min}$ in liquid nitrogen in a hemispherical Dewar flask.

CRITICAL STEP The aim of adding more THF is to ensure fluent stirring in the next step. The added THF needs not be dry and oxygen-free.

21. Take the flask out of the liquid nitrogen and fix it in a stirring plate. Remove the cap of the flask and add distilled water $(5 \mathrm{~mL})$ drop wise with vigorous stirring.

CAUTION The reaction of $\mathrm{LiAlH}_{4}$ with water is highly exothermic and the bubbling of dihydrogen gas is particularly violent. Therefore, initially the addition of water should be drop wise and the addition of the second drop of water should be started only when the gas bubbling caused by the previous drop has ceased. As hydrogen is released during the course of the reaction, the necessary precautions against fire and explosion should be taken. This should be done in a well-vented fume hood.

CRITICAL STEP A lot of excess water is added to make sure the quenching reaction is complete.

22. Let the reaction solution stir at room temperature for 10 minute with the color of the solution changing from black to yellow.

23. Remove the solvents under vacuum by rotary evaporator to obtain a yellow solid.

24. Add $\mathrm{H}_{2} \mathrm{O}(20 \mathrm{~mL})$ and dichloromethane (DCM) $(100 \mathrm{~mL})$ to the yellow solid and stir the mixture for $10 \mathrm{~min}$. Use a spatula to scratch down the product from the wall of the flask while the solution is being stirred.

25. Divide the mixture into three portions. Pour one portion into a separatory funnel $(500 \mathrm{~mL})$ 
and add more $\mathrm{H}_{2} \mathrm{O}(50 \mathrm{~mL})$. Add more DCM into the separatory funnel and shake the resultant mixture. Keep the funnel still for 1 minute to check whether there is an obvious organic phase on the bottom. If there is no phase separation, add more DCM and shake the funnel until the phase separation occurs (Figure S8). Collect the organic phase and extract the aqueous phase with fresh DCM. In total, usually $500 \mathrm{~mL}$ of DCM is required. Combine all the organic solutions and discard the aqueous phase.

\section{TROUBLESHOOTING}

26. For the rest of the two portions of the mixture obtained from Step 24, use the DCM solution that was obtained from Step 25 to extract the desired product with the same procedure that was used in Step 25.

CAUTION Pure DCM should be used to extract the product as in Step 25. However the DCM is reused to extract the product for the other two portions to reduce the cost of the use of pure DCM.

CRITICAL STEP The product can be oxidized by oxygen in the air slowly. Therefore the extraction and the following evaporation of the solvent should be done with 2-3 hours. Longer manipulation times will lead to partial oxidation of the product.

27. Filter the organic solution through a pad of Celite under vacuum to obtain a colorless or slightly yellow solution (Figure S9). Keep the solution in a clean beaker for 2 min and then pour it carefully into a big one-neck round-bottom flask. Remove the solvent by using a rotary evaporator to obtain a colorless or slightly yellow oily product.

CRITICAL STEP Typically, the organic solution should be dried with anhydrous $\mathrm{Na}_{2} \mathrm{SO}_{4}$ or $\mathrm{MgSO}_{4}$ and then filtered. However such an operation is omitted in step 27 in order to avoid potential side reactions of the product, which was found to be sensitive to both acid and base. Instead, the trace water in DCM solution can be removed by keeping the DCM solution in a clean beaker for $5 \mathrm{~min}$ and then pouring the DCM solution out, with the water being left on the wall of the beaker. The residue water from this step will be completely removed in the next step by drying the final product with high vacuum overnight. The purpose to filtering the solution through Celite is to remove the iron oxides from the DCM solution.

28. Dry the product under high vacuum $\left(1 \times 10^{-1} \mathrm{mbar}\right)$ overnight; we put the product inside the glovebox antichamber under vacuum overnight.

CRITICAL STEP This compound is sensitive to acid, base, aluminum oxide and silica gel and as a result, further purification using acid and base or by chromatography is not recommended.

PAUSE POINT This compound is usually obtained in $75 \%$ yield, and it can be stored under inert atmosphere for several months without noticeable loss of purity.

\section{Synthesis of trans-[Fe(CO) $\left.(\mathrm{Cl})\left(\mathrm{PPh}_{2} \mathrm{CH}_{2} \mathrm{CH}=\mathrm{NCHPhCHPhNHCH} \mathrm{CH}_{2} \mathrm{PPh}_{2}\right)\right] \mathrm{BF}_{4}$ TIMING $56 \mathrm{~h}$}

29. In a glovebox, dissolve $\left[\mathrm{Fe}\left(\mathrm{H}_{2} \mathrm{O}\right)_{6}\right]\left[\left(\mathrm{BF}_{4}\right)_{2}\right](1.50 \mathrm{~g}, 4.4 \mathrm{mmol})$ in acetonitrile $(20 \mathrm{~mL})$ with stirring in a vial (volume $20 \mathrm{~mL}$ ). In a separate vial (volume $20 \mathrm{~mL}$ ), dissolve the ligand 
$(S, S)-\mathrm{PPh}_{2} \mathrm{CH}_{2} \mathrm{CH}_{2} \mathrm{NHCHPhCHPhNH}_{2}(1.5 \mathrm{~g}, 3.5 \mathrm{mmol})$ in methanol $(20 \mathrm{~mL})$ with stirring. Weigh sodium methoxide $(0.19 \mathrm{~g}, 3.5 \mathrm{mmol})$ and phosphonium dimer $(0.94 \mathrm{~g}, 1.8 \mathrm{mmol})$ into a big flask $(1000 \mathrm{~mL})$ that is charged with a Teflon-coated stirring bar.

CRITICAL STEP The solvents methanol and acetonitrile should be dry and degassed. We use 1.25 equivalent of $\left[\mathrm{Fe}\left(\mathrm{H}_{2} \mathrm{O}\right)_{6}\right]\left[\left(\mathrm{BF}_{4}\right)_{2}\right]$ relative to the ligand in order to provide a sufficient quantity of iron(II) to form the iron P-N-NH-P bis(acetonitrile) complex because some iron (II) cation may form the $\mathrm{FeCl}_{4}^{2-}$ anion. Make sure that the solutions of $\left[\mathrm{Fe}\left(\mathrm{H}_{2} \mathrm{O}\right)_{6}\right]\left[\left(\mathrm{BF}_{4}\right)_{2}\right]$ and the ligand have been completely dissolved before proceeding to the next step.

30. Add methanol $(150 \mathrm{~mL})$ to the mixture of sodium methoxide and phosphonium dimer in the big flask with stirring. Let the resulting colorless solution stir at room temperature for 2 min.

31. Add the ligand solution and $\left[\mathrm{Fe}\left(\mathrm{H}_{2} \mathrm{O}\right)_{6}\right]\left[\left(\mathrm{BF}_{4}\right)_{2}\right]$ solution to the colorless solution in sequence to afford a pink solution. Seal the flask and let the solution stir at room temperature inside the glovebox overnight (Figure S10).

\section{TROUBLESHOOTING}

32. Bring the flask out of the glovebox, and remove the solvents by using a rotary evaporator in the air to afford a pink solid (Figure S11).

CRITICAL STEP In this step, what we obtain is the P-N-NH-P bis(acetonitrile) iron (II) complex trans-[Fe( $\left.\mathrm{MeCN})_{2}\left(\mathrm{PPh}_{2} \mathrm{CH}_{2} \mathrm{CH}=\mathrm{NCHPhCHPhNHCH} \mathrm{CH}_{2} \mathrm{PPh}_{2}\right)\right]\left(\mathrm{BF}_{4}\right)_{2}$ which is not very sensitive to air. So we can remove the solvents in the air by using a rotary evaporator. However, such an operation should be finished within $1 \mathrm{~h}$; otherwise slow decomposition of the complex will occur leading to a brown solution.

33. Transfer the obtained pink solid to a big Schlenk flask $(250 \mathrm{~mL})$ that is charged with a Teflon-coated stirring bar. Weigh $\mathrm{NaCl}(0.41 \mathrm{~g}, 7.0 \mathrm{mmol})$ into the Schlenk flask and seal it with a rubber septum. Connect the Schlenk flask to the vacuum line and fill the flask with carbon monoxide (at least three vacuum-carbon monoxide cycles). Transfer acetone (150 mL) to the above solid mixture via a positive pressure cannula transfer method (Figure S12). Seal the flask with a glass or rubber septum and stir the pink solution at 1 atm of carbon monoxide (CO) flow for $3 \mathrm{~h}$ at room temperature.

CAUTION Carbon monoxide is highly toxic! Work in a well-vented fume hood. Keep the sash down during all experiments. Use a carbon monoxide detector near the fumehood.

CRITICAL STEP The positive pressure cannula transfer method: Extreme caution should be taken: work in a well-vented fume hood and always keep the sash down. Connect the acetone bomb to the vacuum line and fill the hose with protecting gas (argon or nitrogen) using as least three vacuum-gas cycles. Uncap the solvent bomb under a positive pressure of protecting gas, and then use a rubber septum to seal the solvent bomb. Insert one end of the cannula to the solvent bomb but keep the needle tip above the solvent. Due to the positive pressure above the solvent inside the solvent bomb, the protecting gas will flow from solvent bomb through the cannula to the outside. Keep this flowing for $1 \mathrm{~min}$ to remove the air left inside the cannula. Insert the other end of the cannula into the Schlenk flask which is also 
connected to the protecting gas (here $\mathrm{CO}$ ). Insert a needle $(0.8 \mathrm{~mm} \times 40 \mathrm{~mm})$ into the septum on the Schlenk flask. Now the protecting gas will flow out through this needle. Turn off the inlet of the Schlenk flask while still keeping the inlet of the solvent bomb connected the protecting gas. At the present, the protecting gas will flow out from the solvent bomb through the cannula to the Schlenk flask and then flow out to the air through the needle. Insert one end of the cannula inside the solvent and if the pressure inside the solvent bomb is high enough, the solvent should flow through the cannula to the Schlenk flask. The increased pressure inside the Schlenk flask due to the incoming solvent is released to the air through the needle. Control the solvent transfer rate by adjusting the protecting gas flow. After sufficient solvent has been transferred, put the end of the cannula above the solvent in the solvent bomb, turn on the inlet of the Schlenk flask, and remove the needle in the septum. Remove the cannula from the septum of the Schlenk flask, and then remove the cannula from the septum of the solvent bomb. Substitute the septum of the solvent bomb with its original cap, and turn off the inlet of the solvent bomb. Let the pink solution inside the Schlenk flask stir and adjust the CO flow rate via the regulator of the $\mathrm{CO}$ tank.

34. Remove the solvents by using a rotary evaporator in the air.

35. Connect the Schlenk flask to the vacuum line and fill the flask with carbon monoxide (at least three vacuum-carbon monoxide cycles). Transfer acetone $(150 \mathrm{~mL})$ to the above solid mixture via a positive pressure cannula transfer method. Seal the flask with a glass or rubber septum and stir the pink solution at $1 \mathrm{~atm}$ of $\mathrm{CO}$ flow for $3 \mathrm{~h}$ at room temperature. These operations are the same to those in Step 33.

36. Remove the solvents by using a rotary evaporator in the air.

37. Remove the water in the outer wall of the Schlenk flask completely and then bring the Schlenk flask inside the glovebox.

38. In the glovebox, add DCM $(50 \mathrm{~mL})$ to the Schlenk flask and then keep the flask still for 10 min until a white precipitate on the bottom of the flask is seen. Pour the DCM solution into a round-bottom flask that is charged with a Teflon-coated stirring bar. Use additional DCM $(20 \mathrm{~mL})$ to rinse the white precipitate and pour the DCM solution into the round-bottom flask. Discard the white precipitate in the Schlenk flask. Remove the DCM in the round-bottom flask under vacuum to obtain yellow solid (Figure S13).

39. Add methanol $(15 \mathrm{~mL})$ to the yellow solid obtained in the last step and then stir the resulting brown solution for $30 \mathrm{~min}$ to afford a yellow precipitate (Figure S14).

40. Isolate the crude product via vacuum filtration by using a sintered glass funnel (Figure S15). Discard the filtrate. Dry the crude product completely under high vacuum $\left(1 \times 10^{-1} \mathrm{mbar}\right.$ for $2 \mathrm{~h}$ ) to yield a yellow solid.

PAUSE POINT This crude product can be stored under an inert atmosphere for several months without noticeable loss of purity. However, the color of the solid slowly changes to 
slightly brown after being kept in air overnight.

41. Dissolve the yellow solid in DCM $(100 \mathrm{~mL})$ in the air, and then transfer the solution to a separatory funnel $(500 \mathrm{~mL})$. Add $100 \mathrm{~mL}$ of distilled waster into the separatory funnel. Shake the mixture several times and then keep the funnel still for approx. 5 min to afford the phase separation. Collect the organic phase and add additional DCM $(50 \mathrm{~mL})$ into the funnel to further extract the product left inside the aqueous phase. Combine the two organic phases and remove DCM by rotary evaporator to obtain a yellow solid.

CRITICAL STEP This step should be finished within $1 \mathrm{~h}$ as the iron (II) complex is slightly sensitive to air.

42. Dry the product under high vacuum $\left(1 \times 10^{-1}\right.$ mbar $)$ for more than $3 \mathrm{~h}$; we put the product inside the antichamber the glovebox under vacuum $3 \mathrm{~h}$.

CRITICAL STEP Similar to Step 27, we do not use $\mathrm{Na}_{2} \mathrm{SO} 4$ or $\mathrm{MgSO} 4$ to dry the DCM solution in order to avoid potential side reactions of the iron (II) complex. Instead the trace water left in the final product can be completely removed under high vacuum for $3 \mathrm{~h}$.

43. Bring the product inside the glovebox and transfer it to a bomb (or a flask) with a thick wall and add methanol inside. Also add a small Teflon-coated stirring bar inside the bomb. The ratio of the weight of the crude product to that of methanol is $1: 10.5$. Seal the bomb and bring it out of the glovebox.

CRITICAL STEP Methanol is better to be dry and oxygen-free.

44. Immerse the bomb in a silicone oil bath preheated to $95{ }^{\circ} \mathrm{C}$ (silicone oil in a glass dish with $150 \mathrm{~mm}$ (outer diameter) $\times 75 \mathrm{~mm}$ (height)), and leave it stirring for 5 min until complete dissolving of the solid. Stop both the heating and stirring and keep the bomb still overnight to afford red crystals (Figure 6).

CAUTION The bomb (or the flask) should have a very thick wall and be resistant to high pressure and should be sealed very well. Work in the fume hood and keep the sash down. For larger scale, extreme caution should be taken to avoid an explosion when the mixture is being heated in the oil bath!

45. Isolate the crystals via vacuum filtration by using a Büchner funnel and a filter paper.

PAUSE POINT For this step, normally 65\% (weight) of the crude product will be isolated as beautiful crystals. The crystals can be stored under inert atmosphere for several months without noticeable loss of purity. However, the color of the crystals changes to slightly brown after being kept in air overnight.

46. Remove the solvent of the mother liquor that is obtained from last step to obtain a yellow solid.

47. Bring the crystallization bomb and the yellow solid inside the glovebox and transfer the solid into the bomb together with a small Teflon-coated stirring bar. Add methanol to the 
bomb with a solid/methanol weight ratio of 1:7. Seal the bomb and bring it out of the glove box.

48. Repeat Step 44: immerse the bomb in a silicone oil bath preheated to $95{ }^{\circ} \mathrm{C}$, and leave it stirring for 5 min until complete dissolving of the solid. Stop both the heating and stirring and keep the bomb still overnight to afford red crystals.

49. Repeat Step 45: isolate the crystals via vacuum filtration by using a Büchner funnel and a filter paper. Discard the mother liquor.

50. Combine the crystals obtained from Steps 45 and 49. Dissolve the crystals in DCM and remove the DCM under reduced pressure using vacuum line.

CRITICAL STEP The crystals contain methanol molecules in the lattice. The residual methanol will deactivate the catalysis in the asymmetric transfer hydrogenation reactions.

PAUSE POINT This crystalline compound is usually obtained in $40 \%$ yield on the basis of the quantity of ligand $(S, S)-\mathrm{PPh}_{2} \mathrm{CH}_{2} \mathrm{CH}_{2} \mathrm{NHCHPhCHPhNH}_{2}$, and it can be stored under an inert atmosphere for several months without noticeable loss of purity.

\section{Catalytic asymmetric transfer hydrogenation of ketones and imines TIMING $3 \mathrm{~h}$}

51. In the glovebox, weigh the precatalyst ( $17 \mathrm{mg}, 0.0197 \mathrm{mmol}$ ) into a vial (volume, $20 \mathrm{~mL}$ ) that is charged with a Teflon-coated stirring bar. Add $6.08 \mathrm{~g}$ cold dichloromethane (stored in a fridge at $-30{ }^{\circ} \mathrm{C}$ for more than $30 \mathrm{~min}$ ) into the vial with vigorous stirring. Place the solution into a syringe $(10 \mathrm{~mL})$ equipped with a stainless needle $(0.8 \mathrm{~mm} \times 40 \mathrm{~mm})$ immediately after the dissolution of the solid.

CRITICAL STEP The catalytic activity is highly dependent on the quality of the atmosphere of the glovebox. Catalysis done using the vacuum line usually exhibits significantly reduced catalytic activities.

52. Divide the solution into several equal portions in several vials (volume, $20 \mathrm{~mL}$ ) such that each portion has $0.2 \mathrm{~g}$ of the precatalyst solution. Evaporate the dichloromethane completely under vacuum to obtain a yellow solid. These operations led to a precatalyst quantity of 6.48 $\times 10^{-7} \mathrm{~mol}$ in each vial.

CRITICAL STEP To ensure that the dichloromethane is completely removed, we put the vials inside the antichamber of the glovebox under vacuum for an additional $30 \mathrm{~min}$.

53. Dissolve potassium tert-butoxide $(0.01 \mathrm{~g}, 0.089 \mathrm{mmol})$ into a vial (volume, $20 \mathrm{~mL}$ ) that is charged with a Teflon-coated stirring bar. Add isopropanol $(1.02 \mathrm{~g}, 1.30 \mathrm{~mL})$ into the vial with stirring. Seal the vial and let the solution stir for $15 \mathrm{~min}$ at room temperature to obtain a colorless solution.

CRITICAL STEP The isopropanol should be extremely oxygen-free. The catalytic activity is also highly dependent on the quality of the used isopropanol. 
54. Weigh acetophenone $\left(0.477 \mathrm{~g}, 3.97 \times 10^{-3} \mathrm{~mol}, 6120\right.$ equiv. relative the precatalyst $)$ into a vial (volume, $20 \mathrm{~mL}$ ) that is charged with a Teflon-coated stirring bar. Add isopropanol (5.63 $\mathrm{g}, 7.16 \mathrm{~mL}$ ) into this vial and let the resultant solution stir at room temperature for $1 \mathrm{~min}$.

CRITICAL STEP The acetophenone should be dry and degassed. For the reaction of other substrates, this procedure also works.

55. Pour this solution into one of the vial that was obtained from Step 52 together with stirring bar. Add $1 \mathrm{~g}$ of fresh isopropanol to rinse this vial and then combine all the solution into the vial that contains the precatalyst. Let this mixture stir at room temperature for around 15 min until all the precatalyst that sticks on the wall of the vial has been totally dissolved. A slightly yellow solution should be observed.

56. Weigh $0.06 \mathrm{~g}$ solution of Step $\mathbf{5 3}$ (contains $5.24 \times 10^{-6} \mathrm{~mol}$ of base, 8 equivalents of base relative to the precatalyst) into a vial (volume, $20 \mathrm{~mL}$ ). Add additional fresh isopropanol $(0.501 \mathrm{~g}, 0.64 \mathrm{~mL})$ into this vial and then shake the vial several times to ensure the base diffuses evenly.

57. Use a Pasteur pipettes to transfer the solution of the last step to the solution of Step $\mathbf{5 5}$ with vigorous stirring to initiate the catalysis. At the same time start the timer. Figure S20 shows the reaction at this stage.

58. After $30 \mathrm{sec}$ of reaction, bring the vial out of the glovebox immediately and shake it in the air many times to ensure that the catalytic reaction is completely quenched. We put the vial, after it being brought out of the glovebox, immediately in the stirring pate which is pre-turned on with the highest stirring rate in the air.

CRITICAL STEP For quick quenching the catalysis, the vial should not be sealed.

59. Transfer the solution into a round-bottom flask and remove isopropanol either by rotary evaporator or vacuum line. Adding pentane $(2 \times 10 \mathrm{~mL})$ into the flask to extract the organic product and then filter the solution through a filter paper. Put the filtrate into a Schlenk flask (volume, $50 \mathrm{~mL}$ ) and then remove pentane under reduced vacuum.

60. Bring the Schlenk flask inside the glovebox again.

61. In the glovebox, add fresh isopropanol $(2.0 \mathrm{~g}, 2.54 \mathrm{~mL})$ into one of the vial that contains the catalyst precursor (from Step 52) with vigorous stirring. Let the mixture stir for $15 \mathrm{~min}$ until all the precatalyst that sticks on the wall of the vial has been totally dissolved.

62. Repeat Steps 56: Weigh $0.06 \mathrm{~g}$ solution of Step 53 (contains $5.24 \times 10^{-6} \mathrm{~mol}$ of base, 8 equivalents of base relative to the precatalyst) into a vial (volume, $20 \mathrm{~mL}$ ). Add additional fresh isopropanol $(0.501 \mathrm{~g}, 0.64 \mathrm{~mL})$ into this vial and then add a Teflon-coated stirring bar. 
63. Add fresh isopropanol ( $4.63 \mathrm{~g}, 5.89 \mathrm{~mL})$ into the Schlenk flask of Step $\mathbf{6 0}$ and shake the flask until all the product is completely dissolved. Transfer this solution to the above base solution (Step 62) with stirring.

64. Pour the precatalyst solution of Step 61 into the solution of Step 63 to initiate the catalytic reaction. At the same time start the timer.

CRITICAL STEP As the mixture of acetophenone and 1-phenylethanol (inside the Schlenk flask of Step 60) may still contain base that was introduced in the first-step catalysis, here we do the catalysis by first mixing the new portion of base and the product mixture and followed by adding the precatalyst. This adding sequence is different from the first-step catalysis where base was added to the mixture of precatalyst and the substrate.

65. After $30 \mathrm{sec}$ of reaction, bring the flask out of the glovebox immediately and shake it in the air many times to ensure that the catalytic reaction is completely quenched.

66. Remove the solvent either by rotary evaporator or vacuum line to obtain the crude product.

PAUSE POINT The product $R-1$-phenylethanol is usually obtained in greater than $99 \%$ yield with an enantiomeric excess of $90 \%$. It can be stored in the air for several months without noticeable loss of purity. The gas chromatograph (GC) spectrum of the mixture of Step $\mathbf{6 6}$ is shown in Figure S19. Samples were analyzed using a SHIMADZU GC-2014 gas chromatograph with a chiral column (Rt-bDEXse $30 \mathrm{~m} \times 0.25 \mathrm{~mm}$ ). Hydrogen gas was used as a mobile phase at a column pressure of $38.3 \mathrm{kPa}$. The injector temperature was $250^{\circ} \mathrm{C}$, and the FID temperature was $275{ }^{\circ} \mathrm{C}$ and the oven temperature was $130{ }^{\circ} \mathrm{C}$. The amount of 1-phenylethanol in the sample was determined relative to the amount of the acetophenone. 


\section{TIMING}

Steps 1-12, synthesis of the dimer: Steps 1-4, 90 min-2 h; Step 5-7, 2 h; Steps 8, 12 h; Step 9-12, 6h

Steps 13-28, synthesis of the tridentate ligand: Steps 13-16, 1 h; Steps 17-19, 1 h; Steps 20-23, 1 h; Steps 24-28, $5 \mathrm{~h}$

Steps 29-48, synthesis of the iron complex: Steps 29-31, 12 h; Steps 32-33, 4 h; Steps 34-36, 4 h; Steps 37-38, 2 h; Steps 39-40, 3 h; Steps 41-42; 5h; Steps 43-44, 12 h; Steps 45-47, 1 h; Steps 48, 12 h; Steps 49-50, 1 h

Steps 51-66, catalysis: Steps 51-52, 1 h; Steps 53-55, 20 min; Steps 56-58, 2 min; Steps 59-60, $50 \mathrm{~min}$; Steps 61-65, $17 \mathrm{~min}$; Steps 66; $30 \mathrm{~min}$ 
Table 1 The representative types of ketones and imines and the proposed reaction conditions and results for asymmetric transfer hydrogenation reactions ${ }^{\mathrm{a}}$

\begin{tabular}{|c|c|c|c|c|c|}
\hline entry & substrate & $\begin{array}{l}\text { steps for full } \\
\text { conversion }\end{array}$ & $\begin{array}{l}\text { time for each } \\
\text { step }\end{array}$ & $\begin{array}{c}\text { expected final } \\
\text { yield }\end{array}$ & $\begin{array}{c}\text { expected } \\
\text { ee }(R)\end{array}$ \\
\hline 1 & & $\begin{array}{l}2 \\
\text { (experimental ) }\end{array}$ & $\begin{array}{l}\text { Step 1: } 30 \mathrm{sec} \\
\text { Step 2: } 30 \mathrm{sec} \\
\text { (experimental) }\end{array}$ & $\begin{array}{l}>99 \% \\
\text { (experimental) }\end{array}$ & $\begin{array}{l}90 \% \\
\text { (experimental) }\end{array}$ \\
\hline 2 & & $\begin{array}{l}1 \\
\text { (experimental ) }\end{array}$ & $\begin{array}{l}10 \mathrm{sec} \\
\text { (experimental) }\end{array}$ & $\begin{array}{l}>99 \% \\
\text { (experimental) }\end{array}$ & $\begin{array}{l}91 \% \\
\text { (experimental) }\end{array}$ \\
\hline 3 & & $\begin{array}{l}1 \\
\text { (experimental) }\end{array}$ & $\begin{array}{l}5 \text { min } \\
\text { (experimental) }\end{array}$ & $\begin{array}{l}>99 \% \\
\text { (experimental) }\end{array}$ & - \\
\hline 4 & & $\begin{array}{l}1 \\
\text { (experimental ) }\end{array}$ & $\begin{array}{l}25 \mathrm{sec} \\
\text { (experimental) }\end{array}$ & $\begin{array}{l}>99 \% \\
\text { (experimental) }\end{array}$ & - \\
\hline $5^{\mathrm{b}}$ & & $\begin{array}{l}1 \\
\text { (experimental ) }\end{array}$ & $\begin{array}{l}20 \mathrm{sec} \\
(\text { experimental ) }\end{array}$ & $\begin{array}{l}>99 \% \\
(\text { experimental ) }\end{array}$ & $\begin{array}{l}>99 \% \\
\text { (experimental } \\
\text { ) }\end{array}$ \\
\hline $6^{b}$ & & $\begin{array}{l}1 \\
\text { (experimental ) }\end{array}$ & $\begin{array}{l}180 \mathrm{sec} \\
(\text { experimental ) }\end{array}$ & $\begin{array}{l}>99 \% \\
\text { (experimental) }\end{array}$ & $\begin{array}{l}>99 \% \\
\text { (experimental } \\
\text { ) }\end{array}$ \\
\hline 7 & & 2 & $\begin{array}{l}\text { Step 1: } 1 \mathrm{~min} \\
\text { Step 2: } 30 \mathrm{sec}\end{array}$ & $>99 \%$ & $90 \%$ \\
\hline 8 & & 2 & $\begin{array}{l}\text { Step 1: } 5 \text { min } \\
\text { Step 2: } 2 \text { min }\end{array}$ & $>99 \%$ & - \\
\hline 9 & & 2 & $\begin{array}{l}\text { Step 1: } 20 \mathrm{~min} \\
\text { Step 2: } 20 \mathrm{~min}\end{array}$ & $>99 \%$ & $57 \%$ \\
\hline 10 & & 2 & $\begin{array}{l}\text { Step 1: } 20 \mathrm{~min} \\
\text { Step 2: } 20 \mathrm{~min}\end{array}$ & $>99 \%$ & $34 \%$ \\
\hline 11 & & 2 & $\begin{array}{l}\text { Step 1: } 30 \mathrm{sec} \\
\text { Step 2: } 30 \mathrm{sec}\end{array}$ & $>99 \%$ & $25 \%$ \\
\hline 12 & & 2 & $\begin{array}{l}\text { Step 1: } 1 \mathrm{~min} \\
\text { Step 2: } 30 \mathrm{sec}\end{array}$ & $>99 \%$ & $40 \%$ \\
\hline
\end{tabular}




\begin{tabular}{|l|l|l|l|l|}
\hline 13 & 2 & $\begin{array}{l}\text { Step 1: 3 min } \\
\text { Step 2: 1 min }\end{array}$ & $>99 \%$ & $50 \%$ \\
\hline
\end{tabular}

${ }^{\mathrm{a}}$ General conditions: $[$ Catalyst $]=6.73 \times 10^{-5} \mathrm{M},[\mathrm{KO} t \mathrm{Bu}]=5.45 \times 10^{-4} \mathrm{M}$, [substrate $]=0.412$ $\mathrm{M},[i \mathrm{PrOH}]=12.4 \mathrm{M}, 28{ }^{\circ} \mathrm{C}$; For 2-step reactions, the conditions of each step are same. For entries 1-6 the reaction conditions and the results are obtained directly from current and our previous experiments. For entries 7-13, the proposed reaction conditions and expected results are deduced from the reaction kinetics of these substrates in the previous one-step catalytic reactions (adapted from reference ${ }^{10}$. Reprinted with permission from AAAS; ${ }^{\mathrm{b}}[$ Catalyst $]=5.89$ $\times 10^{-4} \mathrm{M},[\mathrm{KO} t \mathrm{Bu}]=4.71 \times 10^{-3} \mathrm{M},[$ imine $]=5.89 \times 10^{-2} \mathrm{M},[i \mathrm{PrOH}]=12.4 \mathrm{M}, 28^{\circ} \mathrm{C}$. 
Table 2. A comparison of the activity and selectivity of the featured iron catalyst with those of the ruthenium catalysts of Fig. 2 for ATH of ketones.

\begin{tabular}{|c|c|c|c|c|c|c|c|c|c|c|c|c|c|c|c|}
\hline \multirow[b]{2}{*}{ Substrate $^{a}$} & \multicolumn{3}{|c|}{$\mathrm{Fe} \mathrm{KOtBu/iPrOH}\left(28^{\circ} \mathrm{C}\right)$} & \multicolumn{4}{|c|}{ Ru cat. A/KOtBu/iPrOH $\left(22^{\circ} \mathrm{C}\right)$} & \multicolumn{4}{|c|}{ Ru cat. B/ KOtBu/iPrOH $\left(60^{\circ} \mathrm{C}\right)$} & \multicolumn{4}{|c|}{$\mathrm{Ru}$ cat. $\mathrm{C} / \mathrm{NEt}_{3} / \mathrm{HCO}_{2} \mathrm{H}\left(40^{\circ} \mathrm{C}\right)$} \\
\hline & $\begin{array}{l}\text { Loading } \\
(\%)\end{array}$ & Time & ee & $\begin{array}{l}\text { Loading } \\
(\%)\end{array}$ & Time. & ee & Ref. & $\begin{array}{l}\text { Loading } \\
(\%)\end{array}$ & Time. & ee & Ref. & $\begin{array}{l}\text { Loading } \\
(\%)\end{array}$ & Time. & ee & Ref. \\
\hline 1 & 0.02 & $60 \mathrm{~s}$ & 90 & 0.5 & $15 \mathrm{~h}$ & 97 & 11 & 0.005 & $\begin{array}{l}30 \\
\min \end{array}$ & 92 & 13 & 0.1 & $5 \mathrm{~h}$ & 96 & 16 \\
\hline 2 & 0.02 & $10 \mathrm{~s}$ & 91 & & & & & 0.01 & $\begin{array}{l}60 \\
\min \end{array}$ & 99 & 13 & & & & \\
\hline 7 & 0.02 & $\begin{array}{l}1.5 \\
\text { min }\end{array}$ & 90 & 0.5 & $15 \mathrm{~h}$ & 93 & 11 & 0.005 & $5 \mathrm{~min}$ & 97 & 14 & & & & \\
\hline 10 & 0.02 & $\begin{array}{l}40 \\
\min \\
\end{array}$ & 34 & 0.5 & $62 \mathrm{~h}$ & 97 & 11 & & & & & & & & \\
\hline 11 & 0.02 & $60 \mathrm{~s}$ & 25 & & & & & 0.005 & $\begin{array}{l}60 \\
\min \\
\end{array}$ & 86 & 13 & 0.02 & $20 \mathrm{~h}$ & 91 & 17 \\
\hline 12 & 0.02 & $\begin{array}{l}1.5 \\
\mathrm{~min} \\
\end{array}$ & 40 & & & & & & & & & 0.02 & $1.2 \mathrm{~h}$ & 98 & 17 \\
\hline
\end{tabular}

${ }^{\mathrm{a}}$ Numbers correspond to entries of Table 1 


\section{TROUBLESHOOTING}

Troubleshooting advice can be found in Table 3 .

Table 3 Troubleshooting table.

\begin{tabular}{|c|c|c|c|}
\hline Step & Problem & Possible reasons & Solution \\
\hline 3 & $\begin{array}{ll}\text { No reaction } \\
\text { occurs }\end{array}$ & Inactive $\mathrm{KH}$ & $\begin{array}{l}\text { Check the activity of the } \\
\text { KH. Normally the washed } \\
\text { KH should be stored under } \\
\text { inert gas atmosphere or in } \\
\text { glovebox if it is available. }\end{array}$ \\
\hline 25 & $\begin{array}{l}\text { No phase } \\
\text { separation } \\
\text { occurs }\end{array}$ & $\begin{array}{l}\text { In Step 19, the iron (II) } \\
\text { compound was reduced to } \\
\text { low-valent iron species by } \\
\mathrm{LiAlH}_{4} \text { and then in Step } \\
\mathbf{2 1 ~ 2 5} \text { the iron species were } \\
\text { oxidized by oxygen in the air } \\
\text { to iron oxides. Such oxides } \\
\text { have higher density than } \\
\text { water but slightly lower } \\
\text { density than DCM. As a } \\
\text { result, if the volume of DCM } \\
\text { is not sufficient in the } \\
\text { separating funnel the } \\
\text { inorganic oxides are mixed in } \\
\text { the organic phase affording a } \\
\text { gel like suspension }\end{array}$ & $\begin{array}{l}\text { As in Step } \mathbf{2 5} \text {, first divide } \\
\text { the mixture obtained from } \\
\text { Step } 24 \text { into three portions, } \\
\text { and then for the extraction } \\
\text { of each portion add large } \\
\text { quantity of DCM until clear } \\
\text { phase separation can be } \\
\text { seen }\end{array}$ \\
\hline 31 & $\begin{array}{l}\text { Some white } \\
\text { precipitate may } \\
\text { form during the } \\
\text { stirring }\end{array}$ & $\begin{array}{l}\text { These are the inorganic salts } \\
\text { including } \mathrm{KCl} \text { and } \mathrm{KBF}_{4} \text {. }\end{array}$ & $\begin{array}{l}\text { Leave them as these salts } \\
\text { do not affect the reaction. }\end{array}$ \\
\hline
\end{tabular}




\section{ANTICIPATED RESULTS}

The ${ }^{1} \mathrm{H}$ NMR and ${ }^{31} \mathrm{P}$ NMR spectra of the three compounds are provided in the Supplementary Data (Figure S16-S18).

\section{Synthesis of the ( $\left.\mathrm{PPh}_{2} \mathrm{CH}_{2} \mathrm{CHOH}-\right)_{2} \mathrm{Cl}_{2}$}

Yield: $3.72 \mathrm{~g}, 82 \%$, white solid. Two diastereomers in a ratio of $4: 5$ were observed on the basis of ${ }^{31} \mathrm{P}\left\{{ }^{1} \mathrm{H}\right\}$ spectrum and in the ${ }^{1} \mathrm{H}$ and ${ }^{13} \mathrm{C}$ spectra the peaks of the two isomers overlap with each other and cannot be separated. ${ }^{1} \mathrm{H}$ NMR $\left(\mathrm{CDCl}_{3}+4\right.$ drops $\left.\mathrm{CD}_{3} \mathrm{OD}, 600 \mathrm{MHz}\right) \delta$ : $3.75 \sim 3.89$ (m, 2H, $\mathrm{CH}_{2}$, partially overlapping with methanol signal), 4.03 4.18 (m, $2 \mathrm{H}, \mathrm{CH}_{2}$ ), 6.04 6.08 (m, 1H, CHOH), 6.29 6.33 (m, 1H, CHOH), 7.44 7.47 (m, 4H, ArH), 7.58 7.68 (m, 8H, ArH), 7.76 7.79 (m, 2H, ArH), 7.94 8.03 (m, 6H, ArH). ${ }^{13} \mathrm{C}\left\{{ }^{1} \mathrm{H}\right\} \mathrm{NMR}\left(\mathrm{CDCl}_{3}+4\right.$ drop $\left.\mathrm{CD}_{3} \mathrm{OD}, 150 \mathrm{MHz}\right) \delta: 22.4 \sim 23.9(\mathrm{~m}, \mathrm{PCH}), 60.5 \sim 62.0(\mathrm{~m}, \mathrm{PCHOH}), 114.8 \sim 117.0(\mathrm{~m}$, $\operatorname{ArC}), 129.8\left(\mathrm{~d}, J_{\mathrm{CP}}=13.2 \mathrm{~Hz}, \operatorname{Ar} C\right), 130.1 \sim 130.3(\mathrm{~m}, \operatorname{Ar} C), 130.9 \sim 131.0\left(\mathrm{~d}, J_{\mathrm{CP}}=12.5 \mathrm{~Hz}\right.$, $\operatorname{ArC}), 132.8 \sim 132.9(\mathrm{~m}, \operatorname{ArC}), 133.4 \sim 133.5(\mathrm{~m}, \operatorname{Ar} C), 133.6 \sim 133.7\left(\mathrm{~d}, J_{\mathrm{CP}}=9.9 \mathrm{~Hz}, \operatorname{Ar} C\right)$, $135.2(\mathrm{~m}, \operatorname{ArC}), 135.7\left(\mathrm{~d}, J_{\mathrm{CP}}=2.4 \mathrm{~Hz}, \operatorname{ArC}\right) .{ }^{31} \mathrm{P}\left\{{ }^{1} \mathrm{H}\right\} \mathrm{NMR}\left(242 \mathrm{MHz}, \mathrm{CDCl}_{3}+4\right.$ drop $\left.\mathrm{CD}_{3} \mathrm{OD}\right) \delta:$ 12.2, 15.0. Anal. Calcd for $\mathrm{C}_{28} \mathrm{H}_{28} \mathrm{Cl}_{2} \mathrm{O}_{2} \mathrm{P}_{2}$ : C, 63.53; H, 5.33. Found: $\mathrm{C}, 63.40 ; \mathrm{H}$, 5.43. FT-IR $\left(\mathrm{KBr}, \mathrm{cm}^{-1}\right)$ : 617w, 689s, 724m, 743m, 839w, 952w, 995w, 1062m, 1111s, 1393w, $1438 \mathrm{w}, 1484 \mathrm{w}$.

\section{Synthesis of the $(S, S)-\mathrm{PPh}_{2} \mathrm{CH}_{2} \mathrm{CH}_{2} \mathrm{NHCH}(\mathrm{Ph}) \mathrm{CH}(\mathrm{Ph}) \mathrm{NH}_{2}$}

Yield: $1.5 \mathrm{~g}, 75 \%$, white or slightly yellow oil product. ${ }^{1} \mathrm{H} \mathrm{NMR}\left(400 \mathrm{MHz}, \mathrm{CD}_{2} \mathrm{Cl}_{2}\right) \delta: 1.68$ (brs, $\mathrm{NH}$ and $\left.\mathrm{NH}_{2}\right), 2.21\left(\mathrm{~m}, 2 \mathrm{H}, \mathrm{CH}_{2}\right), 2.53\left(\mathrm{~m}, 2 \mathrm{H}, \mathrm{CH}_{2}\right), 3.68\left(\mathrm{~d}, 1 \mathrm{H},{ }^{3} J_{\mathrm{HH}}=7.4 \mathrm{~Hz}\right.$, $\mathrm{NCH}(\mathrm{Ph})), 3.91\left(\mathrm{~d}, 1 \mathrm{H},{ }^{3} J_{\mathrm{HH}}=7.4 \mathrm{~Hz}, \mathrm{NCH}(\mathrm{Ph})\right), 7.14(\mathrm{~m}, 10 \mathrm{H}, \operatorname{Ar} H), 7.31(\mathrm{~m}, 10 \mathrm{H}, \operatorname{Ar} H)$. ${ }^{13} \mathrm{C}\left\{{ }^{1} \mathrm{H}\right\}$ NMR $\left(100 \mathrm{MHz} ; \mathrm{CD}_{2} \mathrm{Cl}_{2}\right) \delta: 29.1\left(\mathrm{~d}, J_{\mathrm{CP}}=12.4 \mathrm{~Hz}, \mathrm{NHCH} \mathrm{H}_{2}\right), 44.3\left(\mathrm{~d}, J_{\mathrm{CP}}=19.2 \mathrm{~Hz}\right.$, $\left.\mathrm{PCH}_{2}\right), 61.9(\mathrm{~s}, C \mathrm{H}(\mathrm{Ph})), 69.5(\mathrm{~s}, \mathrm{CH}(\mathrm{Ph})), 126.8\left(\mathrm{~d},{ }^{3} J_{\mathrm{CP}}=6.9 \mathrm{~Hz}, \operatorname{ArC}(m)\right), 127.1(\mathrm{~s}, \operatorname{ArC})$, $127.9(\mathrm{~s}, \operatorname{Ar} C), 130.0\left(\mathrm{~d},{ }^{4} J_{\mathrm{CP}}=2.6 \mathrm{~Hz}, \operatorname{ArC}(p)\right), 128.4\left(\mathrm{~d},{ }^{3} J_{\mathrm{CP}}=6.4 \mathrm{~Hz}, \operatorname{Ar} C(m)\right), 128.5(\mathrm{~d}$, $\left.{ }^{3} J_{\mathrm{CP}}=7.2 \mathrm{~Hz}, \operatorname{Ar} C(m)\right), 132.5\left(\mathrm{~d}, J_{\mathrm{CP}}=18.7 \mathrm{~Hz}, \operatorname{Ar} C(o)\right), 132.7\left(\mathrm{~d}, J_{\mathrm{CP}}=18.9 \mathrm{~Hz}, \operatorname{Ar} C(o)\right)$, $138.9\left(\mathrm{~d}, J_{\mathrm{CP}}=22.7 \mathrm{~Hz}, \operatorname{Ar} C\right), 139.0\left(\mathrm{~d}, J_{\mathrm{CP}}=22.5 \mathrm{~Hz}, \operatorname{ArC}\right), 141.7(\mathrm{~s}, \operatorname{Ar} C), 144.1(\mathrm{~s}, \operatorname{Ar} C)$. ${ }^{31} \mathrm{P}\left\{{ }^{1} \mathrm{H}\right\}$ NMR (161 MHz; $\left.\mathrm{CD}_{2} \mathrm{Cl}_{2}\right) \delta$ : -20.9. HRMS (ESI-TOF, $\mathrm{CH}_{2} \mathrm{Cl}_{2}$ ) $\mathrm{m} / z$ calculated for $\left[\left(\mathrm{C}_{28} \mathrm{H}_{29} \mathrm{~N}_{2} \mathrm{P}\right)+\mathrm{H}\right]^{+}:$425.2147, found: 425.2150. FT-IR $\left(\mathrm{KBr}, \mathrm{cm}^{-1}\right): 508 \mathrm{~m}, 697 \mathrm{~s}, 741 \mathrm{~s}, 803 \mathrm{~m}$, $1027 \mathrm{~s}, 1069 \mathrm{~m}, 1097 \mathrm{~s}, 1119 \mathrm{~m}, 1179 \mathrm{~s}, 1258 \mathrm{~s}, 1306 \mathrm{w}, 1359 \mathrm{~m}, 1376 \mathrm{w}, 1434 \mathrm{~s}, 1453 \mathrm{~s}, 1481 \mathrm{~s}$, 1493s, 1586m, 1601m, 1814w, 1887w, 1955w, 2832w, 2906w, 2969s, 3028s, 3057s, 3302s, 3351 s. From reference ${ }^{10}$. Reprinted with permission from AAAS.

\section{Synthesis of trans-[Fe(CO) $\left.(\mathrm{Cl})\left(\mathrm{PPh}_{\mathbf{2}} \mathrm{CH}_{\mathbf{2}} \mathrm{CH}=\mathrm{NCHPhCHPhNHCH} \mathbf{C H}_{2} \mathrm{PPh}_{2}\right)\right] \mathrm{BF}_{4}$}

Yield: $1.2 \mathrm{~g}, 40 \%$. ${ }^{1} \mathrm{H}$ NMR $\left(400 \mathrm{MHz}, \mathrm{CD}_{2} \mathrm{Cl}_{2}\right) \delta: 2.87\left(\mathrm{~m}, 1 \mathrm{H}, \mathrm{NHCH}_{2}\right), 2.99$ (m, 2H, $\mathrm{PCH}_{2}$ ), $3.47\left(\mathrm{~m}, 1 \mathrm{H}, \mathrm{NHCH}_{2}\right), 3.99\left(\mathrm{~m}, 2 \mathrm{H}, \mathrm{PCH}_{2}\right), 5.27(\mathrm{~m}, 1 \mathrm{H}, \mathrm{CH}(\mathrm{Ph})), 5.33(\mathrm{~m}, 1 \mathrm{H}, \mathrm{CH}(\mathrm{Ph}))$, 7.17 7.47 (m, 30H, $\mathrm{Ar} H), 7.84(\mathrm{~m}, 1 \mathrm{H}, \mathrm{CH}=\mathrm{N}) .{ }^{13} \mathrm{C} \mathrm{NMR}\left(100 \mathrm{MHz}, \mathrm{CD}_{2} \mathrm{Cl}_{2}\right) \delta: 35.5\left(\mathrm{~d}, J_{\mathrm{CP}}=\right.$ $\left.26.3 \mathrm{~Hz}, \mathrm{PCH}_{2}\right), 45.6\left(\mathrm{~s}, \mathrm{NHCH}_{2}\right), 46.8\left(\mathrm{~d}, J_{\mathrm{CP}}=28.6 \mathrm{~Hz}, \mathrm{PCH}_{2}\right), 70.5(\mathrm{~s}, \mathrm{CH}(\mathrm{Ph})), 80.8(\mathrm{~s}$, $C \mathrm{H}(\mathrm{Ph})), 128.0\left(\mathrm{~d}, J_{\mathrm{CP}}=9.8 \mathrm{~Hz}, \operatorname{Ar} C\right), 128.2\left(\mathrm{~d}, J_{\mathrm{CP}}=10.0 \mathrm{~Hz}, \operatorname{ArC}\right), 128.8 \sim 129.1(\mathrm{~m}, \operatorname{Ar} C)$, $129.4(\mathrm{~s}, \operatorname{ArC}), 130.0 \sim 130.2(\mathrm{~m}, \operatorname{ArC}), 130.5$ (s, $\operatorname{ArC}), 131.0(\mathrm{~s}, \operatorname{Ar} C), 131.1\left(\mathrm{~d}, J_{\mathrm{CP}}=4.8 \mathrm{~Hz}, \operatorname{ArC}\right)$, 132.3 132.4 (m, ArC), $132.9\left(\mathrm{~d}, J_{\mathrm{CP}}=8.2 \mathrm{~Hz}, \operatorname{ArC}\right), 134.1\left(\mathrm{~d}, J_{\mathrm{CP}}=8.1 \mathrm{~Hz}, \operatorname{ArC}\right), 134.3 \sim 134.5(\mathrm{~m}$, $\operatorname{ArC}$ ), $173.1(\mathrm{~s}, C \mathrm{H}=\mathrm{N}), 212.7(\mathrm{~m}, C \mathrm{O}) .{ }^{31} \mathrm{P}\left\{{ }^{1} \mathrm{H}\right\} \mathrm{NMR}\left(161 \mathrm{MHz}, \mathrm{CD}_{2} \mathrm{Cl}_{2}\right) \delta: 58.0,62.6, J_{\mathrm{PP}}=$ $40.2 \mathrm{~Hz}$. HRMS (ESI-TOF, $\mathrm{CH}_{2} \mathrm{Cl}_{2}$ ) $\mathrm{m} / z$ calculated for $\left[\mathrm{C}_{43} \mathrm{H}_{40} \mathrm{ClFeN}_{2} \mathrm{OP}_{2}\right]^{+}$: 753.1654 , found: 753.1640. FT-IR ( $\left.\mathrm{KBr}, \mathrm{cm}^{-1}\right)$ : $1976\left(v_{\mathrm{CO}}\right)$. Anal. Calcd for $\mathrm{C}_{43} \mathrm{H}_{40} \mathrm{BClF}_{4} \mathrm{FeN}_{2} \mathrm{OP}_{2}: \mathrm{C}, 61.42 ; \mathrm{H}$, 4.79; N, 3.33. Found: C, 61.50; H, 4.75; N, 3.25. From reference ${ }^{10}$. . Reprinted with permission 
from AAAS.

\section{MATERIALS}

\section{REAGENTS}

CAUTION All chemicals used in this protocol are potentially harmful. Hence, this protocol should be carried out in a well-vented chemical fume hood while wearing proper personal protective equipment (gloves, lab coat and eye protection).

Potassium hydride (KH; Alfa Aesar, CAS no. 7693-26-7) CAUTION KH reacts violently with acids and ignites upon contact with oxidants, including oxygen. $\mathrm{KH}$ causes severe burns if it is brought into contact with the skin, and, in the dry state, it is pyrophoric

Diphenyl phosphine ( $\mathrm{HPPh}_{2}$; Sigma-Aldrich, CAS no. 829-85-6)

Chloroacetaldehyde diethyl acetal (Sigma-Aldrich, CAS no. 621-62-5)

Hydrochloric acid $\left(\mathrm{HCl}_{(\mathrm{aq})}\right.$; Sigma-Aldrich, CAS no. 7647-01-0) CAUTION $\mathrm{HCl}(\mathrm{aq})$ is highly corrosive, and its vapors irritate the eyes and throat. Carry out this step in a well-vented fume hood

Tetrahydrofuran (THF; Sigma-Aldrich, CAS no. 109-99-9)

Iron(II) chloride ( $\mathrm{FeCl}_{2}$; Strem, CAS no. 7758-94-3)

S,S-1,2-diphenylethylenediamine ( $S, S$-dpen, dpen; Ace Synthesis, CAS no. 29841-69-8)

Sodium methoxide (NaOMe; Sigma-Aldrich, CAS no. 124-41-4)

Lithium aluminum hydride $\left(\mathrm{LiAlH}_{4}\right.$; Sigma-Aldrich, CAS no. 16853-85-3) CAUTION $\mathrm{LiAlH}_{4}$ reacts vigorously with water, acids and alcohols and can easily catch fire. The $\mathrm{LiAlH}_{4}$ should be handled and stored under an inert atmosphere. Small quantities of $\mathrm{LiAlH}_{4}$ should be destroyed by quenching with cold isopropanol.

Methanol (MeOH; Fisher Scientific, CAS no. 67-56-1)

Dichloromethane (DCM, $\mathrm{CH}_{2} \mathrm{Cl}_{2}$; Fisher Scientific, CAS no. 75-09-2)

Iron (II) tetrafluoroborate hexahydrate $\left(\left[\mathrm{Fe}\left(\mathrm{H}_{2} \mathrm{O}\right)_{6}\right]\left[\left(\mathrm{BF}_{4}\right)\right]_{2}\right.$; Sigma-Aldrich, CAS no. 13877-16-2)

Sodium chloride (NaCl; Sigma-Aldrich, CAS no. 7647-14-5)

Acetonitrile (MeCN; Sigma-Aldrich, CAS no. 75-05-8)

Acetone (Sigma-Aldrich, CAS no. 67-64-1)

Carbon monoxide (CO; GR 2.5, Compressed, BOC GASES, CAS no. 630-08-0) CAUTION

Carbon monoxide is highly toxic! Work in a well-vented fume hood. Keep the sash down during all experiments. Using of a carbon monoxide personal detector is highly recommended.

Distilled water

potassium tert-butoxide (KOtBu; Sigma-Aldrich, CAS no. 865-47-4)

Isopropanol (Sigma-Aldrich, CAS no. 67-63-0)

Acetophenone (Sigma-Aldrich, CAS no. 98-86-2)

\section{EQUIPMENT}

Disposable plastic syringes and needles

Thermally controlled stirring plate

Stirring bars, Teflon coated

Glassware: round-bottom flask, sintered glass funnel, Büchner funnel, Büchner flask, graduated cylinders, separating funnel, Pasteur pipettes, Schlenk flask, beakers 
Rubber septa

Rotary evaporator

Oven maintained at $130{ }^{\circ} \mathrm{C}$

Mass balance

Cannula

Hemispherical Dewar flasks

Silicone oil bath, Glass dish, $150 \mathrm{~mm}$ (outer diameter) $\times 75 \mathrm{~mm}$ (height)

Spatula

Weighing paper, filter paper

Access to NMR, infrared (IR), mass spectrometry and elementary analysis (EA), Gas chromatograph with a chiral column

Argon-vacuum dual manifold with vacuum line

Solvent purifier and/or distillation setup

Liquid nitrogen and dry ice

glovebox (argon or nitrogen filled)

Plastic hoses 
ACKNOWLEDGMENTS We thank NSERC for a Discovery grant to R. H. M.

AUTHOR CONTRIBUTIONS W. Z. did all the experiments. R. H. M. directed the research and both authors wrote the manuscript.

COMPETING FINANCIAL INTERESTS The authors declare no competing financial interests.

Reprints and permissions information is available online at http://www.nature.com/reprints/index.html.

1 Lin, G. Q., You, Q. D. \& Cheng, J. F. Chiral Drugs: Chemistry and Biological Action. (John Wiley \& Sons Inc, 2011).

2 Busacca, C. A., Fandrick, D. R., Song, J. J. \& Senanayake, C. H. The Growing Impact of Catalysis in the Pharmaceutical Industry. Adv. Synth. Catal. 353, 1825-1864 (2011).

3 Blaser, H.-U. et al. Selective hydrogenation for fine chemicals: recent trends and new developments. Adv. Synth. Catal. 345, 103-151 (2003).

4 Rodriguez, S. et al. Amine-Tunable Ruthenium Catalysts for Asymmetric Reduction of Ketones. Adv. Synth. Catal. 356, 301-307 (2014).

5 Nugent, T. C. \& El-Shazly, M. Chiral Amine Synthesis - Recent Developments and Trends for Enamide Reduction, Reductive Amination, and Imine Reduction. Adv. Synth. Catal. 352, 753-819 (2010).

6 Magano, J. \& Dunetz, J. R. Large-Scale Carbonyl Reductions in the Pharmaceutical Industry. Org. Proc. Res. Dev. 16, 1156-1184 (2012).

7 Ager, D. J., de Vries, A. H. M. \& de Vries, J. G. Asymmetric homogeneous hydrogenations at scale. Chem. Soc. Rev. 41, 3340-3380 (2012).

8 Johnson, N. B., Lennon, I. C., Moran, P. H. \& Ramsden, J. A. Industrial-scale synthesis and applications of asymmetric hydrogenation catalysts. Acc. Chem. Res. 40, 1291-1299 (2007).

9 Patchett, R. et al. Asymmetric Hydrogenation of Ketones with $\mathrm{H}_{2}$ and Ruthenium Catalysts Containing Chiral Tetradentate $\mathrm{S}_{2} \mathrm{~N}_{2}$ Ligands. Angew. Chem. Int. Ed. 52, 10352-10355 (2013).

Zuo, W., Li, Y., Lough, A. J. \& Morris, R. H. Amino(imino)diphosphines Activate Iron Catalysts in the Asymmetric Transfer Hydrogenation of Ketones and Imines Science 342, 1080-1083 (2013).

Hashiguchi, S., Fujii, A., Takehara, J., Ikariya, T. \& Noyori, R. Asymmetric Transfer Hydrogenation of Aromatic Ketones Catalyzed by Chiral Ruthenium(II) Complexes. J. Am. Chem. Soc. 117, 7562-7563 (1995).

Yamada, I. \& Noyori, R. Asymmetric Transfer Hydrogenation of Benzaldehydes. Org. Lett. 2, 3425-3427 (2000).

Baratta, W. et al. Chiral pincer ruthenium and osmium complexes for the fast and efficient hydrogen transfer reduction of ketones. Organometallics 29, 3563-3570 (2010).

Baratta, W., Chelucci, G., Magnolia, S., Siega, K. \& Rigo, P. Highly Productive CNN Pincer Ruthenium Catalysts for the Asymmetric Reduction of Alkyl Aryl Ketones. Chem. Eur. J. 15, 726-732 (2009).

Cheung, F. K. et al. An investigation into the tether length and substitution pattern of 
arene-substituted complexes for asymmetric transfer hydrogenation of ketones. Org Lett 9 , 4659-4662 (2007).

16 Hayes, A. M., Morris, D. J., Clarkson, G. J. \& Wills, M. A Class of Ruthenium(II) Catalyst for Asymmetric Transfer Hydrogenations of Ketones. J. Am. Chem. Soc. 127, 7318-7319 (2005).

17 Morris, D. J., Hayes, A. M. \& Wills, M. The "Reverse-Tethered" Ruthenium (II) Catalyst for Asymmetric Transfer Hydrogenation: Further Applications. J. Org. Chem. 71, 7035-7044 (2006).

18 Mikhailine, A. A., Lagaditis, P. O., Sues, P., Lough, A. J. \& Morris, R. H. New cyclic phosphonium salts derived from the reaction of phosphine-aldehydes with acid. $J$. Organometal. Chem. 695, 1824-1830 (2010).

19 Lagaditis, P. O., Mikhailine, A. A., Lough, A. J. \& Morris, R. H. Template Synthesis of Iron(II) Complexes Containing Tridentate P-N-S, P-N-P, P-N-N and Tetradentate P-N-N-P Ligands. Inorg. Chem. 49, 1094-1102 (2010).

20 Sues, P. E., Lough, A. J. \& Morris, R. H. Stereoelectronic factors in iron catalysis: Synthesis and Characterization of Aryl-Substituted Iron(II) Carbonyl P-N-N-P Complexes and Their Use in the Asymmetric Transfer Hydrogenation of Ketones. Organometallics 30, 4418-4431 (2011).

21 Zuo, W., Tauer, S., Prokopchuk, D. E. \& Morris, R. H. Iron Catalysts Containing Amine(imine)diphosphine P-NH-N-P Ligands Catalyze both Asymmetric Hydrogenation and Asymmetric Transfer Hydrogenation of Ketones. Organometallics, doi:10.1021/om500479q (2014).

22 Mikhailine, A. A., Kim, E., Dingels, C., Lough, A. J. \& Morris, R. H. Template Syntheses of Iron(II) Complexes Containing Chiral P-N-N-P and P-N-N Ligands. Inorg. Chem. 47, 6587-6589 (2008).

23 Sues, P. E., Demmans, K. Z. \& Morris, R. H. Rational development of iron catalysts for asymmetric transfer hydrogenation. Dalton Trans. 43, 7650-7667 (2014). 